CARINA DOMANESCHI

\title{
PREVALÊNCIA DE COLONIZAÇÃO E INFECÇÃO BUCAL POR CANDIDA E DE CÁRIE NÃO-TRATADA EM PACIENTES PEDIÁTRICOS COM AIDS
}




\section{Carina Domaneschi}

Prevalência de colonização e infecção bucal por Candida e de cárie não-tratada em pacientes pediátricos com aids

Tese apresentada à Faculdade de Odontologia da Universidade de São Paulo, para obter o título de Doutor, pelo Programa de Pós-Graduação em Odontologia.

Área de concentração: Diagnóstico Bucal

Orientadora: Profa. Dra. Esther Goldenberg Birman

São Paulo 


\section{FOLHA DE APROVAÇÃO}

Domaneschi C. Prevalência de colonização e infecção bucal por candida e de cárie não-tratada em pacientes pediátricos com aids [Tese de Doutorado]. São Paulo: Faculdade de Odontologia da USP; 2007.

São Paulo,

\section{Banca Examinadora}

1) $\operatorname{Prof}(a) . \operatorname{Dr}(a)$.

Titulação:

Julgamento:

Assinatura:

2) Prof (a). Dr (a).

Titulação:

Julgamento: Assinatura:

3) Prof (a). Dr (a).

Titulação:

Julgamento:

Assinatura:

4) Prof (a). Dr (a).

Titulação:

Julgamento:

Assinatura:

5) Prof (a). Dr (a).

Titulação:

Julgamento:

Assinatura: 
ADeus,

Presente em lodos os dias da minhar existência, me fortalecendo, amparando e iluminando os meus ideais.

A minha familia, mäe Caetanina (in memorian) pelo sew amon elerno, e pela liçäo deixada de carisma, persistência e amor ao próximo; Cristiane e Carlos, meus irmäos queridos e pacienciosos comigo em mais esta etapa; e men pai, para o qual näo existem palawas para experessar tudo que sinto... Pai zeloso e dedicado, incentivadov e men espetho profissional para a ánea acadêmica e cientifica. Obrigada a vocês pela liçäo de amos e compreensĩo...

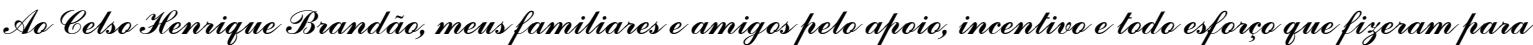
que en fudesse alcançar esta meta.

Este trabalto é dedicado também, e com especial carinho, a todas as crianças atendidas pelo Serviço de Infectologia do Instituto da Criança do Hospital das Clínicas, vazão central desta pesquisa cientifica, porém vitimas inocentes de um dos grandes males do século $\mathscr{X}$ Tue continua a desafiar a sabedoria humana - a aids!' - A essas crianças devo men crescimento como pessoc humana sensivel ao sofrimento atheio, e como profissional! 
Algradecimentos especiais

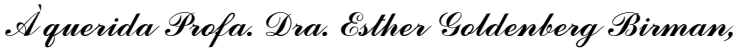

Expressão de liderança, perseverança e dedicação ì vida universitária. Durante esses anos de comsivência foi minha incentivadora e uma orientadora amiga que sempre procurow me ajudar e aconseltars, instigando-me a perseverar com honestidade na caneina acadêmico-cientifica. Altanço esta importante elapar de minha jomada universitária graças aos incentiveos dessa pesson singular, de quem guardarei os melhores conselhos e oremplo a seguir como paradigma. Meus agradecimentos säo lambém pela preocupação com a minha formação profissional e moral, e por ter acreditado em men potencial.

Ao estimado Nestre,

Prof. Dr. Dante Antonio Nigliari,

Ëm nada é diferente minhar gratidão por teres encontrado um tempo e prostado apoio, orientaçäo e incentivo extras nas elafeas finais de minha P̈ós-Suaduação. Algradeço pela demonstração de amizade e pela semprepresente disponibilidade para ajudar-me não só neste habalho, mas no decomer de outras opontumidades de minha formação acadêmico-cientifica. Obrigado lambém por acreditar em men potencial!' 


\section{AGRADECIMENTOS}

À Universidade de São Paulo e especialmente a Faculdade de Odontologia da USP, esta representada pelos Professores Doutores Carlos de Paula Eduardo, Diretor e Suzana C. M. Orsini de Sousa, Vice-Diretor; e ao Departamento de Estomatologia, na pessoa do seu Chefe Prof. Dr. Rhodney Garcia Rocha pela oportunidade da realização deste trabalho;

À Profa. Dra. Heloisa Helena de Sousa Marques, chefe do Serviço de Infectologia do Instituto da Criança do Hospital das Clínicas da Universidade de São Paulo que tornou possível o contato com as crianças atendidas por essa Instituição, bem como o exame, coleta de materiais e acesso aos dados clínicos das mesmas, sem o que seria inviável a realização desta pesquisa;

Ao Prof. Dr. José Eduardo Costa Martins, chefe do Laboratório de Micologia Médica do Instituto de Medicina Tropical de São Paulo do Hospital das Clínicas da Universidade de São Paulo pelas facilidades oferecidas e apoio no desenvolvimento deste trabalho;

À Profa. Dra. Claudete Rodrigues Paula, responsável pelo Laboratório de Leveduras Patogênicas do Instituto de Ciências Biomédicas da Universidade de São Paulo pela acolhida que me permitiu o desenvolvimento de parte do cultivo e identificação dos microrganismos, objeto deste trabalho, e pela oportunidade de aprendizado, sempre com muita amizade e carinho;

Aos Professores Doutores, Gilberto Marcucci, Fernando Ricardo Xavier da Silveira, Jayro Guimarães Junior, Norberto Nobuo Sugaya e Celso Augusto Lemos Junior, responsáveis por minha formação em Estomatologia, muito obrigado pela amizade e confiança em mim depositadas; 
Às professoras do Diagnóstico Bucal e Odontopediatria da Faculdade de Odontologia de Araraquara - UNESP, Maria Regina Sposto, Mirian Aparecida Onofre, Claudia Maria Navarro, Elaine Maria Sgavioli Massucato e Ângela Cristina Cilense Zuanon, minhas amigas e primeiras incentivadoras à pesquisa;

À Iracema Mascarenhas Pires, Maria Cecília Forte Muniz e Ana Carolina Fragoso Motta, pela sempre-sincera amizade, compreensão e incentivos a minha carreira acadêmico-científica;

À Débora Bizetto Massarente, amiga dedicada e colaboradora em muitas etapas deste trabalho de pesquisa, por compartilhar também de meus momentos de aprendizado, alegria e tristeza;

Ao Prof. Dr. José Leopoldo Ferreira Antunes pela paciência e carinho ao receber-me e prestar-me assessoria científica na realização do tratamento estatístico dos dados, interpretação e discussão dos resultados;

Às médicas do Instituto da Criança, Dras. Samantha Andrade, Helena Keico Sato, Vera Lúcia M. Borrelli, Adriana Melo de Faria e Uderlaine dos Santos Meneguci e Fabiana Ariston Silgueira, pela valiosa colaboração e principalmente pela amizade e tamanha humildade ao transmitirem-me valiosos conhecimentos...;

Às micologistas Elizabeth Maria Heins Vaccari, Natalina Takahashi, Roseli Santos de Freitas (IMT-USP), a Luciana da Silva Ruiz, Geórgia Carla Matuura Batista, Ériques Gonçalves da Silva, Mauro Cintra Giudice, Adriana Reis de Menezes, Elza Helena da Silva (ICB-USP) que gentilmente colaboraram para o meu aprendizado de muitas técnicas laboratoriais e metodologias específicas, sempre com amizade e carinho;

Às pessoas de Giovana Letícia Hernandez Arriagada e Da. Antonia Chagas dos Santos do IMT-USP; às de Satiko Uehara e Ademir (Mineiro) do ICB-USP; e a de Aparecida Ferreira Andrade da FO-USP pelo carinho, amizade e pelos colaborações prestadas; 
Aos meus amigos da Estomatologia Clínica, pela amizade e companheirismo sempre presentes em especial à Ana Rosa Maurício, Camila de Barros Gallo e à amiga da Patologia Bucal Tatiana Nayara Libório dos Santos e da Radiologia Thásia Luiz D. Ferreira . "Os amigos são a forma de Deus cuidar de nós...”;

À Vânia M.B.O. Funaro, pela normalização do trabalho, Maria Aparecida Pinto pela formatação e Suely Caffazi Pattri pela elaboração da ficha catalográfica. Às bibliotecárias da FO-USP pela atenção e esclarecimentos dados com grande profissionalismo durante todas etapas de minha Pós-Graduação e formação profissional;

Às funcionárias Cátia Tiezzi dos Santos, Nair Hatsuko Tanaka Costa, Alessandra Moreira de Lima e Donata Cristina de Lima Moreira, da Seção de Pós-Graduação da FO-USP, pela atenção a mim dispensada;

À CAPES pelo auxilio financeiro concedido para a realização deste trabalho;

À CAPES pela Bolsa de Doutorado que me possibilitou a dedicação em tempo integral à realização desta pesquisa científica, e à PROAP/CAPES pelos auxilios financeiros complementares para a realização e divulgação deste trabalho;

Para finalizar, uma das grandes conquistas ao realizar este trabalho foi o aumento de meu círculo de amizades, com quem compartilhei meus sentimentos de alegria e momentos de risos ou lágrimas. Agradeço a todos, embora sem poder nomeá-los para não estender demasiadamente estes "Agradecimentos". Porém, cito algumas dessas pessoas que de modo especial se destacaram e estarão sempre comigo, na memória e no coração:

Rita Diná Mascarenhas Pires, Silvana de Almeida, Raquel Mendonça da Silva, Roselicy da Costa Barbosa, Rosangela de Oliveira Lima, Edmond Haddad Junior, Valdir Aparecido Pires, Afonso Francisco Gomes, Ney Soares de Oliveira, Umberto Tomaes da Cruz, Sibele Sarti Penha, Kazue Kanegane, Maria Angela Mimura, Wilson Afonso Junior, Anelena Antuniazzi (in memorian), Maria Fernanda Roquette Ferreira, Daniela Marques Campos, Daniela Prata, Thais Leite de Camargo, Mayalu 
Dantes, Maria Amélia Mascarenhas Dantes, Daniela Schimidell, Kleber Cortês Bonifácio, Hallissa Simplício, Judith Maria de Jesus, Márcia Andrea Ferreira, Dra. Cidia Vasconcelos, Graziela Fernandes de Castro Malagutti, Sandra Bonifácio, Márcia Maria dos Santos, Wilma Aparecida Vieira, Vera Lúcia dos S. C. Almeida, Sonia Maria de Oliveira, Adauto Lopes de Menezes, Silvia Regina dos Santos, Laerte Zanon, Marilda Helena Ribeiro, Christiane N. Trindade Zanotti, Vânia de Almeida Lima Furlan, Maria de Fátima Agrela Soares, Irany Cantão dos Santos e as enfermeiras do leito dia do Instituto da Criança.

Enfim, a todos que contribuíram para este trabalho, 
Domaneschi C. Prevalência de colonização e infecção bucal por Candida e de cárie não-tratada em pacientes pediátricos com aids [Tese de Doutorado]. São Paulo: Faculdade de Odontologia da USP; 2007.

\section{RESUMO}

Este estudo avaliou a prevalência de colonização e infecção bucal por Candida, bem como a de cárie não-tratada em crianças com aids atendidas no ambulatório de Infectologia, Instituto da Criança do HC-FMUSP. Foram examinados 117 pacientes em idade de 3-15 anos (média 9,4 anos) para o estudo da prevalência de Candida, e 125 na mesma faixa de idade para a avaliação da necessidade de tratamento de restauração dentária. Condições clínicas gerais, medicação em uso e dados laboratoriais foram obtidos do prontuário médico referente a cada paciente. O exame bucal seguiu as normas da OMS (1996); questionário sócio-demográfico foi respondido pelos cuidadores. A prevalência de cárie foi avaliada em relação às condições socioeconômicas, comportamentais e clínicas dos pacientes. Para o estudo de associação entre as variáveis foi utilizada a análise de regressão de Poisson com ajuste por idade. Os resultados indicaram $62 \%$ de prevalência de colonização bucal por Candida (54\%-72\%, intervalo de confiança 95\%). A manifestação clínica da candidose bucal foi baixa entre os pacientes avaliados (7\%), considerando que a maioria das crianças apresentava baixa contagem CD4, alta carga viral e colonização por Candida. Foi identificada associação entre cultura positiva com uso freqüente de antibióticos (razão de prevalência $R P=1,44$ ), sulfa $(R P=1,23)$, alteração de mucosa bucal $(R P=1,55)$ e prevalência de cárie nãotratada $(\mathrm{RP}=1,93)$; associação negativa ocorreu quando em uso de medicamentos anti-retrovirais $(\mathrm{RP}=0,65)$. Candida albicans foi a espécie mais isolada $(80 \%)$; 
espécies não-albicans corresponderam a $18 \%$. Nenhum caso de colonização por $C$. dubliniensis foi identificado através de testes fenotípicos. A freqüência de cárie nãotratada em ao menos um dente decíduo ou permanente foi de $58 \%$ dentre os pacientes, porcentagem mais elevada que a verificada entre crianças sem aids de mesma idade no Estado de São Paulo. Cuidador familiar com ensino secundário completo representou fator de redução da prevalência de cárie, $(R P=0,51)$, enquanto aglomeração domiciliar $(R P=1,53)$ e freqüência diária de ingestão de açúcar $(R P=1,44)$ associaram com prevalência mais elevada. Carga viral maior que 100.000 cóp/ml $(R P=1,41)$ e manifestação de sintomas severos da aids $(R P=1,39)$ também associaram com pior condição dentária. $\mathrm{O}$ presente estudo mostra baixa prevalência de lesão bucal, indicativo de que as terapias anti-retrovirais para a doença aids produz resultados clínicos bem satisfatórios, e que crianças com aids têm maior necessidade de tratamento dentário do que crianças HIV negativas. A elevada prevalência de colonização por Candida e de cárie não-tratada em crianças com aids reforça a necessidade e importância da integração do dentista na equipe multiprofissional que atende a esses pacientes.

Palavras-Chave: Candida; Infecção HIV; Aids; Cárie dentária; Condições sóciodemográficas; 
Domaneschi C. Prevalence of oral colonization and infection by Candida and of untreated caries in pediatric patient with aids [Tese de Doutorado]. São Paulo: Faculdade de Odontologia da USP; 2007.

\section{ABSTRACT}

This study assessed the prevalence of oral colonization and infection caused by Candida, as well of untreated caries in pediatric patients with aids attended at the Clinic for Infection Diseases, Child Institute, Clinic Hospital of the University of São Paulo, Brazil. The prevalence of colonization and infection by Candida was evaluated among hundred seventeen, 3 to 15-years-old (mean age of 9.4 years) children, and the requirement for dental treatment among 125 children of the same age group. General clinical condition, medications in use and laboratories findings were obtained from the medical chart of each patient. Dental examination followed WHO guidelines for oral health surveys; data on demographic conditions were extracted from questionnaires filled in by familial caregivers. Prevalence of untreated caries were evaluated in relation to socioeconomic, behavioral and clinical conditions. Poisson regression analysis adjusted by age assessed covariates for the prevalence of untreated dental caries and Candida colonization. Results indicated $62 \%$ of prevalence of oral colonization by Candida (54\%-72\%, confidence interval $95 \%$ ). Clinical manifestation of oral candidosis was low (7\%) despite of low CD4, and both high viral load and Candida colonization detected among most children. Positive result for Candida colonization associates with frequent use of antibiotics (prevalence ratio $P R=1.44)$, sulfa drugs $(P R=1.23)$, alteration on the oral mucosa $(P R=1.55)$, and untreated dental caries ( $P R=1.93)$; negative association occurred with the use of antiretroviral therapies $(P R=0.65)$. Candida albicans was the most frequent 
species (80\%); non-albicans species 18\%. Phenotipic testes did not allowed to detect any colonization by $C$. dubliniensis. Prevalence of untreated dental caries either on one deciduous or one permanent tooth affected $58 \%$ of the patients, a rate higher than that registered among the same group age, non-HIV-children in the state of São Paulo, Brazil. Being attended by high school graduated caregivers represented a reduction factor of prevalence of caries $(P R=0.51)$, while household crowding $(P R=1.53)$ and daily sugar intake $(P R=1.44)$ was associated with a higher prevalence of caries. Viral load higher than 100,000 copies/ml $(P R=1.41)$ and severe symptom of aids manifestations $(P R=1.39)$ also associated with poorer dental status. The present study revealed low prevalence of oral lesions, an indicative that antiretroviral therapies results satisfactory for aids treatment and HIV+/aids-children, and that aids-affected children have higher prevalence of untreated caries than in non-affected children in the same group age. The high prevalence of both Candida colonization and untreated caries in HIV+/aids-children reinforces the importance of a health-care professional to the interdisciplinary team that assists those patients.

Keywords: Candida; HIV infection; aids; Dental caries; Socio-demographic condition 


\section{LISTA DE FIGURAS}

Figura 5.1 - Prevalência das espécies de Candida isoladas da mucosa bucal de crianças com aids assistidas no ICr/HC - USP, 2006 55

Figura 5.2 - Prevalência (intervalo de confiança 95\%) de necessidade de tratamento em crianças com aids assistidas no ICr/HC - USP, 2006 56 


\section{LISTA DE TABELAS}

Tabela 5.1 - Associação entre cultura positiva e características sócio-demográficas de crianças com aids assistidas no ICr/HC - USP, 2006

Tabela 5.2 - Associação entre cultura positiva e característica comportamental de crianças com aids assistidas no $\mathrm{ICr} / \mathrm{HC}$ - USP, 2006

Tabela 5.3 - Associação entre cultura positiva, condição clínica e uso contínuo de medicamento de crianças com aids assistidas no ICr/HC - USP, 2006

Tabela 5.4 - Associação entre cultura positiva e uso combinado de TARV de crianças com aids assistidas no ICr/HC - USP, 2006

Tabela 5.5 - Fatores associados na cultura positiva de crianças com aids assistidas no ICr/HC - USP, 2006

Tabela 5.6 - Associação multivariada entre cultura positiva e características das crianças com aids assistidas no ICr/HC - USP, 2006

Tabela 5.7 - Associação entre a prevalência de cáries não-tratadas e características sócio-demográficas de crianças com aids assistidas no $\mathrm{ICr} / \mathrm{HC}$ - USP, 2006.

Tabela 5.8 - Associação entre a prevalência de cárie não-tratada e característica comportamental de crianças com aids assistidas no $\mathrm{ICr} / \mathrm{HC}$ - USP, 2006

Tabela 5.9 - Associação entre a prevalência de cárie não tratada, condição clínica e uso contínuo de medicamento de crianças com aids assistidas no $\mathrm{ICr} / \mathrm{HC}$ - USP, 2006

Tabela 5.10 - Associação multivariada entre a prevalência de cárie não tratada e características das crianças com aids assistidas no $\mathrm{ICr} / \mathrm{HC}$ - USP, 2006 


\section{LISTA DE ABREVIATURAS E SIGLAS}

\begin{tabular}{|c|c|}
\hline ICR-HC & Instituto da Criança, Hospital Clínica \\
\hline IMT-USP & Instituto de Medicina Tropical da Universidade de São Paulo \\
\hline ICB-USP & Instituto de Ciências Biomédicas da Universidade de São Paulo \\
\hline FO & Faculdade de Odontologia \\
\hline aids & Síndrome da Imunodeficiência Adquirida \\
\hline CD4 & receptor de superfície de linfócitos auxiliares \\
\hline CV & carga viral \\
\hline HAART & $\begin{array}{l}\text { Highty Active Anti Retroviral Therapy (Terapia Anti-Retroviral } \\
\text { Alta Atividade) }\end{array}$ \\
\hline TARV & terapia anti-retroviral \\
\hline HIV & Vírus da Imunodeficiência Humana \\
\hline HIV+ & $\begin{array}{l}\text { paciente portador do Vírus da Imunodeficiência Humana sem } \\
\text { sinais clínicos da AIDS }\end{array}$ \\
\hline HPV & papiloma vírus humano \\
\hline IP & inibidor protease \\
\hline ELISA & Enzyme Linked Immuno Sorbent Assay \\
\hline ITRN & inibidor da transcriptase reversa análogo de nucleosídeo \\
\hline ITRNN & inibidor da transcriptase reversa não-análogo de nucleosídeo \\
\hline RNA & ácido ribonucléico \\
\hline DNA & ácido desoxirribonucléico \\
\hline C. albicans & Candida albicans \\
\hline C. dubliniensis & Candida dubliniensis \\
\hline & espécies de Candida \\
\hline
\end{tabular}


amostra padrão de Candida albicans do Instituto de Ciências Biomédicas da Universidade de São Paulo

Ciências Biomédicas da Universidade de São Paulo ágar Staib

CAF

Agar citrato ácido férrico caféico

RAPD

Random Amplified Polymorphic DNA

PCR

Polymerase Chain Reaction

CDC

Centro de Controle e Prevenção de Doenças

WHO

World Health Organization

OMS

Organização Mundial de Saúde

ceo-d

número de dentes decíduos cariados, com extração indicada

CPO-D

dentes cariados, perdidos e obturados

CPI

Índice Periodontal Comunitário

IC

intervalo de confiança

RP

razão de prevalência

$\mathrm{NaCl}$

cloreto de sódio

q.s.p.

quantidade suficiente para

$\mu \mathrm{g}$

micrograma

$\mu \mathrm{l}$

microlitro

rpm

rotações por minuto

${ }^{\circ} \mathrm{C}$

graus centígrados

et al

el alli, e outros 


\section{SUMÁRIO}

p.

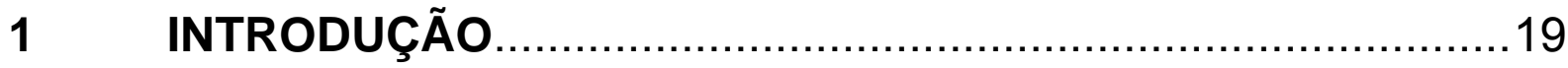

2 REVISÃO DA LITERATURA .......................................24

$2.1 \quad$ Etiologia e epidemiologia da aids pediátrica ....................................24

2.2 Diagnóstico da infecção pelo HIV em crianças ..................................26

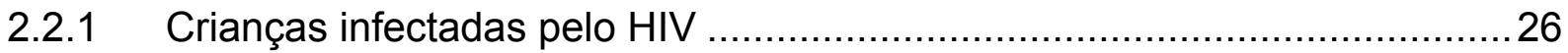

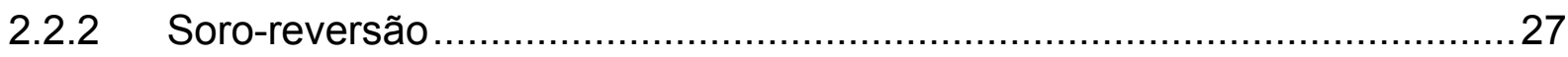

2.3 Classificação da infecção pelo HIV e parâmetros virológicos em pacientes menores de 13 anos.............................................. 27

2.4 Manifestações bucais e condição dentária em crianças HIV+laids ......29

2.5 Formas clínicas da candidose bucal em crianças HIV+laids.................33

2.6 Espécies de Candida isoladas de crianças HIV+laids ......................... 34

2.7 Diferenciação entre Candida albicans e C. dubliniensis através de métodos fenotípicos........................................................... 35

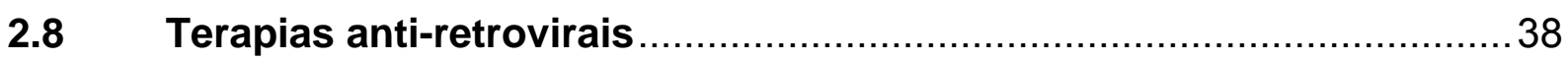

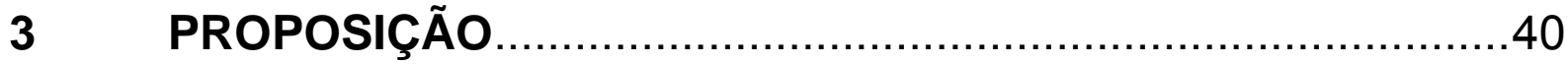

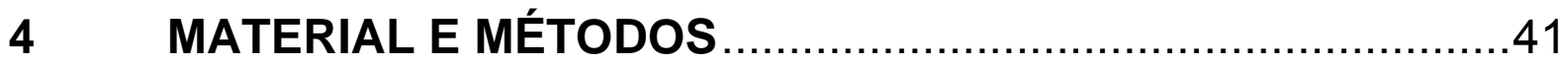

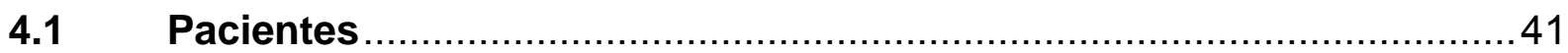

4.2 Dados clínicos e laboratoriais do paciente .................................42

4.3 Método de coleta, transporte e processamento das amostras de

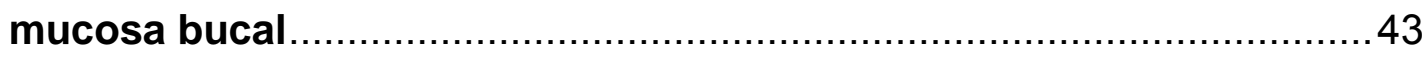

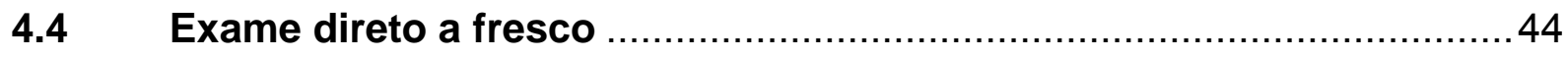

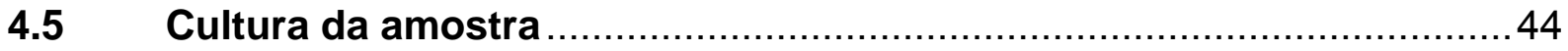

4.6 Identificação das leveduras ............................................................ 45

4.7 Diferenciação das espécies C. albicans e C. dubliniensis por testes

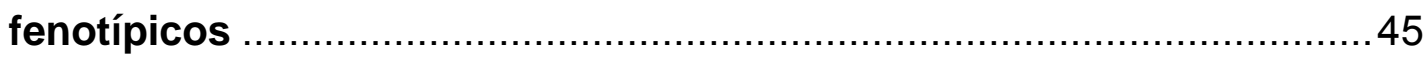

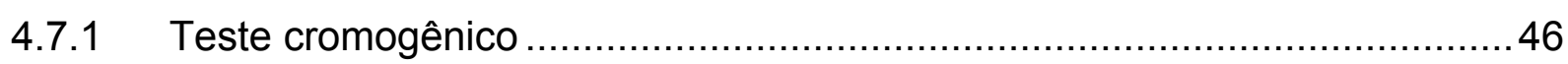


4.7.2 Método de "crescimento a $42^{\circ} \mathrm{C}$ " ...................................................... 46

4.8 Prevalência de cárie e aspectos clínicos da mucosa bucal .................46

4.9 Dados sócio-demográficos e comportamentais ..............................47

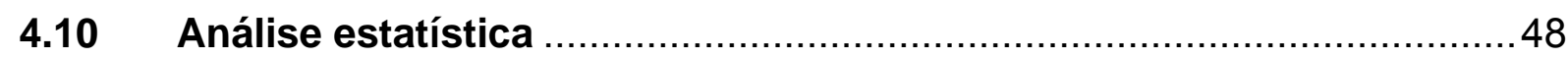

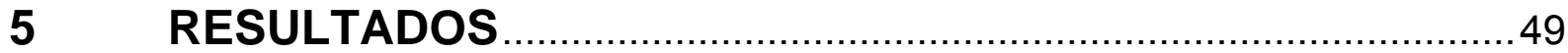

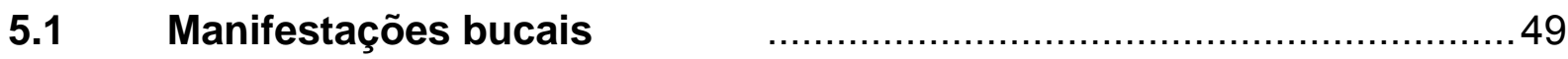

5.2 Colonização bucal por Candida sp ............................................. 49

5.3 Identificação das leveduras isoladas ....................................... 54

5.4 Testes fenotípicos utilizados para diferenciação de C. dubliniensis entre amostras identificadas como $C$. albicans.............................. 55

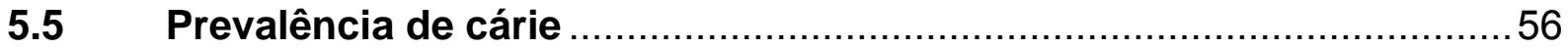

6 DISCUSSÃO

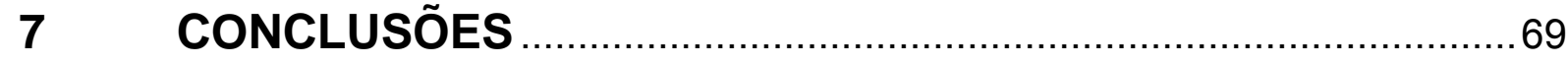

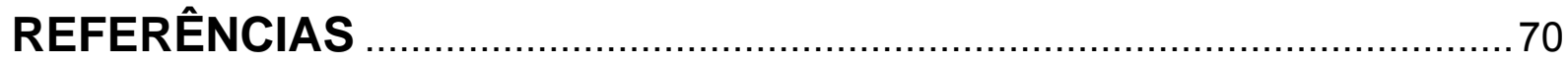

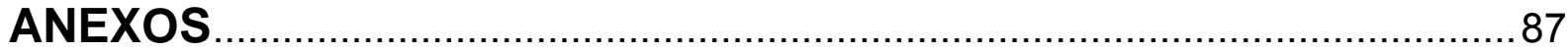




\section{INTRODUÇÃO}

A síndrome da imunodeficiência adquirida (aids), doença de origem infecciosa, causada pelo vírus da imunodeficiência humana (HIV) e transmissível através do sangue e secreções humanas, atinge o sistema imunológico do portador, deixando-o predisposto às infecções oportunistas (COTRAN; KUMAR; ROBBINS, 1996). A doença aids corresponde ao estágio mais avançado da infecção pelo HIV e se caracteriza pela falência progressiva do sistema imunológico, uma ação resultante da replicação e disseminação do vírus no organismo infectado. Devido ao seu caráter pandêmico e de alta taxa de mortalidade, a aids tornou-se, em escala mundial, um dos mais complexos problemas de saúde pública.

Os primeiros casos de aids em adultos foram relatados nos Estados Unidos da América do Norte em 1981 (GOTTLIEB et al., 1981); no Brasil, o primeiro registro em adulto data de 1982 e, em criança, de 1983 (BRASIL, 2006). Ao longo da década de 1980, a infecção pelo HIV em mulheres brasileiras foi responsável pela transmissão vertical do vírus, a qual ocorre durante a gestação, no momento do parto ou durante o aleitamento, afetando de $25 \%$ a $50 \%$ das crianças nascidas dessas mulheres (ANDRADE, 1990). Até 2006, crianças menores de 13 anos infectadas pelo HIV, e que já manifestavam os sintomas da aids, totalizavam 19.825 casos no país, dos quais, $81,1 \%$ devido a transmissão vertical, e $8,3 \%$ com forma de transmissão não determinada (AIDS, 2006; BRASIL, 2006).

As características clínicas da doença em crianças apresentam certos aspectos que ocorrem com menor freqüência nos adultos, principalmente em relação às glândulas parótidas. Os sinais e sintomas gerais da infecção pelo HIV em 
pediatria incluem febre, linfadenopatia generalizada, hepatoesplenomegalia, diarréia crônica ou recorrente, pneumonia crônica, e deficiência no desenvolvimento pôndero-estatural e/ou psicomotor. Em relação aos tecidos bucais, a infecção pelo HIV ocasiona principalmente hipertrofia indolor da parótida, candidose bucal persistente, e ainda redução do fluxo salivar (COSTA et al., 1998; CALVELLI; RUBINSTEIN, 1990; RUBINSTEIN, 1990; TOVO et al., 1992).

Múltiplos são os fatores que contribuem para os diferentes padrões de progressão da doença em crianças, entre os quais se incluem a época da infecção, carga viral, genótipo e fenótipo viral, resposta imune e constituição genética do indivíduo. Portanto, acompanhamento clínico, avaliação imunológica pela contagem de linfócitos T auxiliares (CD4 e CD8), e carga viral pela amplificação do RNA das partículas virais circulantes são fundamentais para se avaliar o prognóstico, orientar decisões terapêuticas e monitorar a eficácia do tratamento (BRASIL, 2004b).

Achados clínicos bucais na infecção pelo HIV em pediatria revelam alta prevalência de necessidades de tratamento odontológico, principalmente de cárie dentária (FABRO et al., 2002; HOWELL et al., 1992; MADIGAN et al., 1996), e lesões da mucosa bucal, algumas das quais consideradas primeiro diagnóstico da aids, como a candidose bucal recorrente (BRASIL, 2004a; FONSECA; CARDOSO; POMARICO, 2000; MAGALHÃES et al., 2001; NICOLATOU et al., 1999). Baixa condição socioeconômica, uso constante de agentes antimicrobianos e medicamento anti-retroviral em solução oral açucarada são características usuais das crianças com HIV+/aids. Tais condições são relatadas como alto fator de risco para o surgimento de cáries e lesões na mucosa bucal (BRETZ et al., 2000; COSTA et al., 1998; MACKIE; BENTLEY, 1994). 
O tratamento odontológico pode contribuir com a condição geral do paciente, inclusive psicológica, e, acima de tudo, a qualidade de vida das crianças HIV+/aids, representando um importante instrumento para melhoria da sua condição sistêmica. Contudo, essas crianças nem sempre são tratadas de forma correta, devido à falta de motivação familiar e de integração entre serviços médicos e odontológicos nas unidades de saúde em que são atendidas (CASTRO et al., 2001; WALDMAN, 1991).

O desenvolvimento de infecções oportunistas durante a aids decorre fundamentalmente de alterações no sistema imunológico do paciente, caracterizadas pelo decréscimo de linfócitos CD4 (RUBINSTEIN, 1988; SCOTT et al., 1989). Nas crianças, em particular, além do sistema imunológico imaturo, o decréscimo desse tipo de linfócitos favorece a progressão da doença (BROWN et al., 2000; MONIACI et al., 1990).

A candidose bucal é fortemente indicativa do desenvolvimento subseqüente da aids, podendo as lesões bucais se apresentarem clinicamente na forma pseudomembranosa ou eritematosa, ou combinação dessas duas formas, sendo o aspecto das lesões similar ao que é observado nas candidoses bucais de indivíduos não infectados pelo HIV (AXELL et al., 1997; BAZIN, 1995; CECCOTTI, 1995; GROOPMAN, 1990; PETERSEN et al., 1993; SAMARANAYAKE; CHEUNG; SAMARANAYAKE, 2002; STUDEN-PAVLOVICH; CHIGURUPATI, 1997).

A candidose bucal é a manifestação mais freqüente em crianças infectadas pelo HIV, com prevalência oscilando entre $20 \%$ e $72 \%$. Tem caráter persistente por longos períodos, embora com alguns períodos de remissão, e freqüentemente resistente a terapias antifúngicas convencionais, manifestações essas que podem ocorrer também nos primeiros seis meses de vida de bebês saudáveis (DELGADO; AGUIRRE, 1997; DARWAZEH; AL-BASHIR, 1995; KADIR; UYGUN; AKYUZ, 2005; 
LYNCH, 1994; MATTOS-GRANER et al., 2001). As lesões causadas pela candidose podem se estender até o esôfago, causando dificuldades na deglutição e agravando a imunidade devido ao comprometimento alimentar (BAZIN, 1995; DUPONT et al., 1994; PETERSEN et al., 1993; STUDEN-PAVLOVICH; CHIGURUPATI, 1997).

A colonização bucal por espécies de Candida tem sido amplamente investigada em adultos HIV+/aids (FERNANDEZ FEIJOO; DIZ DIOS, 2002; MIGLIORATI; BIRMAN; CURY, 2004; LEWIS; SAMARANAYAKE; LAMEY, 1991; SAMARANAYAKE; HOLMSTRUP, 1989), entretanto, o número de artigos relatados sobre este tema é comparativamente menor em crianças HIV+/aids, e dentre os quais se destacam os de Bosco et al. (2003), Miziara e Weber (2006) e Nicolatou et al. (1999).

Candida albicans é a espécie mais freqüentemente associada a infecções fúngicas da cavidade bucal, em adultos e crianças, e a mais virulenta entre as espécies do gênero Candida (SAMARANAYAKE; MACFARLANE, 1990). Entretanto, outras espécies de Candida, como C. glabrata, C. parapsilosis, C. guilliermondii, e C. kruzei também são patogênicas e encontradas em pessoas HIV- ou HIV+/aids (BOSCO et al., 2003; COSTA et al., 2006; DARWAZEH; AL-BASHIR, 1995; FIDEL JR; VAZQUEZ; SOBEL, 1999; KADIR; UYGUN; AKYUZ, 2005; MIGLIORATI et al., 2004; SAMARANAYAKE; SAMARANAYAKE, 1994; WEEMS JR, 1992).

Candida dubliniensis, espécie recentemente descrita por SULLIVAN et al. (1995), e isolada principalmente da mucosa bucal de indivíduos infectados pelo HIV (COLEMAN et al., 1997; SULLIVAN et al., 1995), tem sido encontrada também em pacientes clinicamente saudáveis (HANNULA et al., 2000; PINJON et al., 1998). Desde sua caracterização em 1995, C.dubliniensis tem atraído a atenção de pesquisadores, pois esta levedura apresenta características fenotípicas e 
genotípicas semelhantes às da $C$. albicans, diferindo desta em relação à freqüência de isolamento, características patogênicas, resistência a agentes antifúngicos e maior capacidade de aderência às células da mucosa bucal (ALVES et al., 2002; ARIKAN et al., 2003; DELGADO; AGUIRRE, 1997). Porém, ainda há poucos estudos sobre a infecção causada pela Candida dubliniensis na população pediátrica (BROW et al., 2000; CIMOLAI; DAVIS; TROMBELY, 2002; MEIS et al., 1999).

Com a introdução da terapia anti-retroviral (TARV), os casos de candidose bucal em crianças HIV+/aids foram reduzidos acentuadamente. O amplo acesso à TARV, principalmente quando combinada a duas ou mais drogas, incluindo inibidores de protease, vem resultando em melhor qualidade de vida para os pacientes (BRASIL, 2001; MIZIARA; ARAUJO FILHO; WEBER, 2006; VARGAS; JOLY, 2002) e, de acordo com Aguirre et al. (1999), Castro (1998), Patton et al. (2000), essa terapia combinada tem sido responsável pela diminuição na prevalência de candidose bucal.

O presente estudo tem os seguintes objetivos: (i) identificar as espécies de Candida presentes na mucosa bucal desses pacientes com aids, bem como a freqüência de ocorrência de cada espécie; (ii) avaliar a manifestação clínica da candidose bucal nessas crianças; (iii) verificar a prevalência de cárie não-tratada em crianças com aids e (iv) avaliar se cáries não-tratadas podem estar associadas com fatores relativos à condição socioeconômica dessas crianças (renda, grau de escolaridade dos cuidadores e condição de moradia, aglomeração familiar, número de irmãos do paciente), a aspectos comportamentais (dieta, higiene bucal e acesso ao dentista), condições clínicas (marcadores clínicos do desenvolvimento da aids e freqüência do consumo de medicamentos açucarados). 


\section{REVISÃO DA LITERATURA}

\subsection{Etiologia e epidemiologia da aids pediátrica}

O HIV é um retrovírus com genoma da família Retroviridae (retrovírus) e subfamília Lentivirinae, possuindo grande afinidade pelo receptor CD4 presente na superfície de células integrantes do sistema imunológico, e, para multiplicar-se, necessita de uma enzima denominada transcriptase reversa, que permite a transcrição do RNA viral para uma cópia de DNA viral na célula linfócito T CD4 do hospedeiro. Uma vez infectados pelo HIV os linfócitos T CD4 são destruídos progressivamente, levando a uma conseqüente depressão do sistema imunológico, o que favorece o aparecimento de infecções oportunistas e de neoplasias malignas (WILKES et al., 1988). Esse vírus pode infectar outras células que expressam a molécula CD4 em sua superfície, como células dendríticas e macrófagos (GROOPMAN, 1990; MILLER, 1997; WILKES et al., 1988).

Atualmente, verifica-se um aumento na incidência da doença entre pessoas do sexo feminino. Como conseqüência direta disso, e da ocorrência de transmissão vertical do vírus, o número de crianças afetadas começa a ocupar espaço na epidemiologia da infecção pelo HIV (BRASIL, 2000b). De acordo com Magalhães et al. (2001), a infecção pelo HIV na cidade de São Paulo tem se expandido, sendo agora, uma das principais causas de morte no grupo pediátrico.

Considera-se aids pediátrica quando a infecção pelo HIV ocorre em pessoas de zero a 13 anos de idade (AIDS INSTITUTE, 1998; GUIDELINES, 2000; 
LEGGOTT, 1992); infectados acima de 13 anos são incluídos nas estatísticas de adultos (PETERSEN et al., 1993). Os primeiros casos de aids pediátrica no mundo foram reportados por Ammann et al. (1982) e O'Reilly et al. (1982); no Brasil, o primeiro registro data de 1983 (AIDS, 1998).

O HIV pode ser transmitido por transfusão de sangue contaminado, relação sexual sem preservativo e transmissão vertical. A transmissão vertical pode ocorrer no útero, em qualquer período da gestação, ou durante o parto normal, cesariana, e através do aleitamento materno (BRASIL, 1995; CHIGURUPATI; RAGHAVANS, STUDEN-PAVLOVICH, 1996; GHERSEL; RODRIGUES; TANNOUS, 1999; LIMA; SILVEIRA; BIRMAN, 1994; SANDE; VOLBERDING, 1995). Pequeno número de crianças ainda adquire o HIV por ser vítima de abuso sexual, uso de drogas injetáveis, transfusões sangüíneas ou uso de derivados do sangue (AIDS INSTITUTE, 1998; GUIDELINES, 2000).

No Brasil, a forma de transmissão predominante em crianças infectadas pelo HIV é a vertical (OLIVEIRA et al.,1996), a qual contribui para $25 \%$ dos casos. A transmissão do vírus, na grande maioria desses casos não acontece ao longo da gestação, mas durante o parto quando a criança entra em contato com sangue materno contaminado, permitindo a penetração do vírus no organismo por meio de lesões microscópicas comuns em recém-nascidos (TRAUMMAN; MONTEIRO, 1998). Importante salientar, todavia, que o fato de a mãe ter o vírus HIV não significa que a criança necessariamente torne-se infectada. Crianças nascidas de mães portadoras do vírus HIV serão sempre soropositivas ao nascimento, e somente $15 \%$ a $50 \%$ delas permanecerão soropositivos após os 18 meses de idade (HERNANDEZ; BOJ, 1996; LEGGOTT, 1992), constituindo 2\% do total dos casos relatados de aids em nações em desenvolvimento. A média de transmissão vertical 
é estimada entre $15 \%$ a $20 \%$ na Europa, $16 \%$ a $30 \%$ nos Estados Unidos e $25 \%$ a 40\% nas nações em desenvolvimento (CHIGURUPATI; RAGHAVANS; STUDENPAVLOVICH, 1996).

O risco de transmissão do HIV da mãe para o filho pode ser reduzido em até $67 \%$ com o uso de AZT durante a gravidez, ou no momento do parto, complementado com administração da mesma droga ao recém-nascido por 6 semanas (AIDS, 2004).

\subsection{Diagnóstico da infecção pelo HIV em crianças}

\subsubsection{Crianças infectadas pelo HIV}

Considera-se infectada pelo HIV a criança que apresentar resultado positivo em duas amostras testadas pelos seguintes métodos: (i) cultivo de vírus (ii) quantificação de RNA viral plasmático, (iii) detecção do DNA pró-viral, ou (iv)

antigenemia p24 após dissociação ácida de imunocomplexos (BRASIL, 2004a). Qualquer desses testes devem ser realizados duas semanas após o nascimento. Em crianças com idade igual ou maior que 18 meses, o diagnóstico deve ser confirmado em duas amostras de sangue coletadas em momentos diferentes e por meio de dois resultados reagentes para detecção de HIV-1 e HIV-2 pelo menos um dos testes confirmatório realizados em recém-nascidos (BRASIL, 2004a). 


\subsubsection{Soro-reversão}

Soro-reversão em pacientes com idade abaixo de 18 meses deve ser confirmada por duas amostras negativas pelo método de cultivo do vírus, ou de detecção de RNA e DNA viral, realizado em dois períodos diferentes, entre 1 e 6 meses de vida (BRASIL, 2004a). Soro-reversão em pacientes com idade igual ou maior que 18 meses deve ser confirmada com obtenção de amostra negativa através de teste de detecção para anticorpos anti-HIV (BRASIL, 2004a). Estes dois critérios indicados para se detectar a soro-reversão aplicam-se a crianças que não estejam sendo amamentadas por mãe HIV-positiva; amamentação, em qualquer período, expõe a criança ao HIV, requerendo que esta seja submetida a nova rotina diagnóstica (BRASIL, 2004a).

\subsection{Classificação da infecção pelo HIV e parâmetros virológicos em pacientes menores de 13 anos}

A classificação da infecção pelo HIV utiliza sistema alfanumérico baseado em parâmetros clínicos e imunológicos internacionalmente aceitos (quadros 2.1 e 2.2), propostos em 1994 pelo Centro de Controle e Prevenção de Doenças (CENTERS FOR DISEASE CONTROL AND PREVENTION, 1994). 


\begin{tabular}{|lcccc|}
\hline $\begin{array}{l}\text { Alteração } \\
\text { imunológica }\end{array}$ & $\begin{array}{c}\mathrm{N}=\text { ausência de } \\
\text { sinais elou de } \\
\text { sintomas clínicos }\end{array}$ & $\begin{array}{c}\mathrm{A}=\text { sinais elou } \\
\text { sintomas } \\
\text { clínicos leves }\end{array}$ & $\begin{array}{c}\mathrm{B}=\text { sinais elou } \\
\text { sintomas } \\
\text { clínicos } \\
\text { moderados }\end{array}$ & $\begin{array}{c}\mathrm{C}=\text { sinais elou } \\
\text { sintomas } \\
\text { clínicos } \\
\text { severos }\end{array}$ \\
\hline Ausente (1) & $\mathrm{N} 1$ & $\mathrm{~A} 1$ & $\mathrm{~B} 1$ & $\mathrm{C} 1$ \\
Moderado (2) & $\mathrm{N} 2$ & $\mathrm{~A} 2$ & $\mathrm{~B} 2$ & $\mathrm{C} 2$ \\
Grave (3) & $\mathrm{N} 3$ & $\mathrm{~A} 3$ & $\mathrm{~B} 3$ & $\mathrm{C} 3$ \\
\hline
\end{tabular}

Quadro 2.1 - Classificação da infecção pelo HIV em crianças e adolescentes menores de 13 anos

\begin{tabular}{|c|c|c|}
\hline \multirow{3}{*}{$\begin{array}{l}\text { Alteração } \\
\text { imunológica }\end{array}$} & \multicolumn{2}{|c|}{ Contagem de LT- CD4 ${ }^{+}\left(\right.$cél $\left./ \mathrm{mm}^{3}\right)$} \\
\hline & \multicolumn{2}{|c|}{ Idade } \\
\hline & 1 a 5 anos & 6 a 12 anos \\
\hline Ausente (1) & $\geq 1000$ & $\geq 500$ \\
\hline Moderada (2) & 500-999 & $200-499$ \\
\hline Grave (3) & $<500$ & $<200$ \\
\hline
\end{tabular}

Foi considerada evidência de supressão imunológica moderada ou severa para valores menores ou iguais a 350 céls $/ \mathrm{mm}^{3}$ para crianças maiores de 13 anos (CENTERS FOR DISEASE CONTROL AND PREVENTION, 1994).

A deterioração imunológica está relacionada com a progressão da doença. A contagem absoluta de linfócitos T CD4 varia muito nas diferentes faixas etárias, o que não é observado com os valores percentuais desses elementos sangüíneos. A interpretação das variações da contagem de linfócitos T CD4 deve ser cuidadosa, devendo ser lembrado que, na criança, pode haver diminuição transitória, mesmo frente a outras doenças intercorrentes leves e imunizações (BRASIL, 2004a). 
A definição de prognóstico não deve ser pautada somente na carga viral, deve-se levar em conta, principalmente, a contagem de linfócitos T CD4 e a evolução clínica de cada paciente, especialmente quando são crianças com menos de 30 meses de idade. Para crianças com mais de 30 meses de idade, níveis de viremia plasmática superior a 100.000 cóp/ml e contagem de linfócitos T CD4 inferior a 15\% são indicadores de piora clínica (categoria C) ou morte (BRASIL, 2004a).

\subsection{Manifestações bucais e condição dentária em crianças HIV+laids}

Embora a aids tenha sido descrita em 1981, poucas são as publicações sobre manifestações bucais em crianças (BRUNELLE, 1992). Manifestações bucais do HIV+/aids em pacientes adultos estão relativamente bem descritas na literatura (BRAVO et al., 2006; DATTANI; GARATRA, 1993; MARGIOTTA et al., 1999; RANGANATHAN et al., 2000), mas dados comparativos para HIV+/aids pediátrico são limitados. Embora haja muita informação sobre contaminação de crianças africanas pelo HIV, há poucos registros na literatura sobre manifestações dentais e bucais do HIV nas crianças daquele continente (BLIGNAUT, 2007; JABRA-RIZK et al., 2001). Poucas publicações da América do Norte (NAIDOO; CHIKTE, 2004) fazem referência a esse fato para crianças dessa região do continente americano. No Brasil, os estudos sobre lesões bucais em decorrência da infecção pelo HIV em crianças são aqueles de Bosco e Birman (2002) e Bosco et al. (2003), Magalhães et al. (2001), Pinheiro et al. (2004), Ranganathan et al. (2000) e Santos et al. (2001). 
A infecção pelo HIV resulta em profunda imunossupressão, tornando o paciente susceptível ao desenvolvimento de várias infecções oportunistas e neoplasias. A cavidade bucal é particularmente susceptível a infecções, pois é abrigo de grande número de microorganismos; esse número aumenta em condições de imunossupressão, causando lesões fúngicas (candidoses, queilite angular), virais (herpes simples, citomegalovírus, HPV), bacterianas (periodontites, gengivites) e neoplasias malignas (linfomas, sarcoma de Kaposi). A freqüência dessas lesões oscila nas diferentes populações em função do maior ou menor acesso a atendimentos médico e odontológico, medicação e nutrição adequada (FLAITZ et al., 2001; PONGSSIRIWET et al., 2003). Lesões bucais são, freqüentemente, os primeiros sinais de infecção pelo HIV em crianças (HOWELL et al., 1996; KLEIN et al., 1984; MAGALHÃES et al., 2001; NICOLATOU et al., 1999; RAMOS-GOMEZ et al., 2000; SCHIODT; PINDBORG, 1990).

Avaliação da prevalência de manifestações bucais foi realizada por Flaitz et al. (2001) com um grupo de 173 crianças HIV+ de ambos os sexos, na faixa etária de 6 a 12 anos. Nesse artigo os autores registraram manifestações bucais em 55\% das crianças, cujas lesões e respectivas freqüências foram: candidose (29\%), úlceras (15\%), alterações das glândulas salivares (9\%), gengivite necrosante aguda $(5 \%)$, eritema gengival linear $(4 \%)$, molusco contagioso gengival $(3 \%)$, verruga vulgar (2\%), leucoplasia pilosa $(2 \%)$ e herpes zoster (1\%); citam ainda a erupção dentária retardada como alteração comum em crianças infectadas pelo HIV. Os índices de manifestação bucal e candidose obtidos por Flaitz et al. (2001) são semelhantes aos registrados por Chan, Milnes e King. (1994), Fonseca, Cardoso e Pomarico (2000), Magalhães et al. (2001), Nicolatou et al. (1999), Pinheiro et al. (2004), Ranganathan et al. (2000) e Silva, Lopes e Barreto (2002). 
Em adultos, e segundo Bravo et al. (2006), a candidose bucal é a lesão mais comum (61\%), o que confirma registros anteriores feitos por Samaranayake e Holmstrup (1989), Samaranayake (1992), seguida pela leucoplasia pilosa (53\%), leucoplasia bucal (34\%), hiperpigmentação melânica (38\%), papiloma (13\%), eritema linear gengival (8\%), UAR (5\%), e sarcoma de Kaposi $(5 \%)$. Os resultados obtidos por Bravo et al. (2006) corroboram aqueles de Dattani e Ganatra (1993), Lloyd (1996) e Ranganathan et al. (2000).

Candidose bucal é a infecção mais comumente detectada em crianças $(60 \%$ dos pacientes pediátricos) (KATZ et al., 1993; LEGGOT, 1992), sendo a forma pseudomembranosa a mais encontrada (CHAN; MILNES; KING, 1994; LEGGOT, 1992; NAIDOO; CHIKTE, 2004).

Manifestações bucais estão diretamente relacionadas com o grau de imunossupressão e algumas lesões podem ser consideradas como indicadoras de progressão da infecção pelo HIV em crianças (RAMOS-GOMEZ, 2002; SANTOS et al., 2001). A candidose bucal é considerada um sinal de prognóstico desfavorável da doença (KATZ et al., 1993).

O HIV provoca, indiretamente, lesões nas glândulas salivares (ATKINSON et al., 1990) e o uso de drogas anti-retrovirais leva à diminuição de produção de saliva (xerostomia), favorecendo o aparecimento de infecções por Candida (DATRY, 1992). A saliva de pacientes xerostômicos tem $\mathrm{pH}$ baixo, o que favorece a atividade da proteinase produzida por C. albicans (ATKINSON et al., 1990; MCCARTHY, 1992; ODDS; VAN NUFFEL; DAMS, 1988).

Maior risco de alterações nos tecidos dentários também é relatado para crianças infectadas pelo HIV. Esses riscos estão basicamente relacionados ao comprometimento imunológico progressivo, aos efeitos da medicação na fisiologia 
salivar e microbiota bucal, menor adesão dessa população aos tratamentos dentários, bem como a fatores econômicos e nutricionais (CASTRO et al., 2001; FERGUSSON; NACHMAN; BERENTSEN, 1997; GRANDO et al., 2003).

Examinando 104 crianças com idade até 15 anos, infectadas pelo HIV, Tofsky et al. (2000) verificaram que elas apresentavam uma incidência de cárie na dentição decídua mais elevada que o grupo controle, não afetado pela doença. Souza et al. (1996) também identificaram que crianças infectadas pelo HIV estavam sujeitas a indicadores mais elevados de prevalência e severidade do ataque de cárie, tanto na dentição decídua como na permanente, em relação às não infectadas.

Fabro et al. (2002) chamaram atenção para a elevada prevalência de necessidades de tratamento odontológico de crianças com aids, as quais apresentaram, além de grande número de cáries, a presença de manifestações estomatológicas decorrentes da aids, como candidoses, linfadenopatia cervical e aumento do volume das glândulas parótidas.

Grando et al. (2003) e Peres, Bastos e Latorre (2000) estudaram fatores como condição socioeconômica, comportamental e cultural, renda familiar, acesso a informações referentes à aids, adesão ao tratamento, e suas relações com o desenvolvimento de doenças em crianças brasileiras e americanas e encontraram uma forte associação entre esses fatores com o aparecimento de lesões bucais. 


\subsection{Formas clínicas da candidose bucal em crianças HIV+laids}

A candidose bucal manifesta-se sob as formas pseudomembranosa, eritematosa e hiperplásica; no entanto, em crianças HIV+/aids as formas pseudomembranosa e eritematosa são as mais freqüentes, sendo a forma crônica hiperplásica raramente observada (MAGALHÃES et al., 2001). A forma pseudomembranosa é uma infecção aguda que permanece por vários meses ou muitos anos em pacientes que fazem uso de corticosteróide tópico ou em aerosol, e também em indivíduos infectados pelo HIV e outros pacientes imunocomprometidos. Essa forma se manifesta como uma placa branca na superfície da mucosa bucal ou labial, na língua e palato, sendo facilmente removida, mas deixando uma base eritematosa, erosiva (COSTA et al., 1998; SAMARANAYAKE, 1996). A placa branca consiste de um emaranhado de hifas fúngicas, blastósporos, fibrina, bactérias, células inflamatórias e células descamativas epitelial (HOLMSTRUP; SAMARANAYAKE, 1990).

A candidose em sua forma eritematosa é associada com o uso de corticosteróide, antibióticos de amplo espectro, e recentemente com a doença HIV. Também pode se desenvolver como conseqüência de uma candidose pseudomembranosa aguda, quando a pseudomembrana se desprende. Clinicamente, a forma eritematosa se apresenta como uma placa vermelha, freqüentemente na área mediana do dorso da língua, no palato ou mucosa bucal; geralmente assintomática, quase não perceptível, passa despercebida se o clínico não estiver atento. No paciente HIV+ é comum ocorrer lesão eritematosa no palato (SAMARANAYAKE; HOLMSTRUP, 1989). 
A forma hiperplásica, ou leucoplásica é a menos comum. Ela se caracteriza como lesão crônica, de crescimento discreto e que varia de pequena, palpável e translúcida até ocupar áreas mais amplas, de aspecto denso e com formação de placa opaca não raspável. Essa forma de candidose geralmente acomete áreas da comissura labial, uni- ou bilateral, sendo menos freqüente na superfície da língua e está associada com transformação maligna, esta relatada em $15 \%$ dos casos de candidose bucal (BODEY, 1993; WALKER; ARENDORF, 1990).

Em seu estudo com crianças HIV+, Nicolatou et al. (1999) constataram que $18 \%$ delas apresentavam candidose bucal, sendo a forma eritematosa a mais freqüente $(38 \%)$, seguida pela pseudomembranosa $(11 \%)$, e com um só caso progredindo da eritematosa para a pseudomembranosa. No entanto, num estudo similar com crianças HIV+/aids, realizado por Fonseca, Cardoso e Pomarico (2000), a forma predominante foi a pseudomembranosa (21\%), seguida da eritematosa com apenas $5 \%$ dos casos.

\subsection{Espécies de Candida isoladas de crianças HIV+laids}

Candidose bucal, causada principalmente por C. albicans, é a infecção oportunista por fungos mais comumente encontrada em pacientes adultos com aids, sendo que nos mesmos a incidência desta infecção varia de $43 \%$ a $93 \%$ dos casos enquanto a ocorrência de espécies de Candida não-albicans em adultos com aids varia entre $14 \%$ e $35 \%$, com predomínio da C. krusei, seguida por C. glabrata e C. tropicalis (BRAWNER; HOVAN, 1995; LITTLE et al., 1994; MILAN, 1997; RODERO 
et al., 1995). Em pacientes pediátricos HIV+/aids, C. albicans têm sido descrita como a mais freqüente (BOSCO, 1998; MONIACI et al., 1993). Segundo Kadir, Uygun e Akyuz (2005), numa população saudável de crianças turcas a espécie prevalente foi C. albicans (84,8\%), seguida por C. parapsilosis, C. krusei, C. kefyr, C. famata e C. tropicalis. Bosco et al. (2003), Ugun-Can, Kadir e Akyuz (2007) corroboram essa prevalência de C. albicans nos grupos de pacientes infantis com aids por eles investigados.

Embora C. albicans seja a espécie fúngica oportunista mais frequentemente isolada de pacientes com aids, uma espécie mais recentemente caracterizada, $C$. dubliniensis, vem ganhando considerável atenção devido a sua quase exclusiva associação com indivíduos HIV+/aids (BROWN et al., 2000).

\subsection{Diferenciação entre C. albicans e C. dubliniensis através de métodos fenotípicos}

Candida dubliniensis foi isolada em candidoses eritematosas, principalmente em mucosa orofaringeana de pacientes HIV+ (ODDS; VAN NUFFEL; DAMS, 1998; SULLIVAN et al., 1999), e também da mucosa bucal e vaginal de pacientes não portadores do HIV (POLACHECK et al., 2000).

Nas rotinas laboratoriais, $C$. dubliniensis pode ser facilmente confundida com C. albicans, pois ambas apresentam tubo germinativo positivo, produzem clamidoconídios e são semelhantes nos testes bioquímicos; diferenças são detectadas apenas em relação à prevalência, a certas características de virulência, e 
à capacidade de desenvolver resistência, in vitro, ao medicamento antifúngico fluconazol (SULLIVAN et al., 1995; SULLIVAN; COLEMAN, 1998; SULLIVAN et al., 1999).

Métodos de identificação mais rápida foram desenvolvidos, e os laboratórios têm usado com freqüência o produto CHROM-ágar Candida, meio cromogênico que confere coloração verde-claro a C. albicans e verde-escuro a C.dubliniensis (GIUSIANO; MANGIATERRA, 1998). Os testes com esse produto têm diminuído a dificuldade de identificação dessas espécies e de algumas outras leveduras, sendo, portanto, de grande valia em estudos clínicos (ODDS; BERNAERTS, 1994).

A literatura traz exemplo de como o emprego do teste com CHROMagar fornece elementos que permitem o isolamento de leveduras e direcionam os trabalhos de identificação; estes passam a ter maior grau de confiabilidade quando complementados com outros testes desenvolvidos para essa finalidade. Foi empregando as técnicas de cultura à temperatura de $42^{\circ} \mathrm{C}$, e do CHROMagar, em 155 amostras infectadas com diferentes espécies de Candida que Milan et al. (2001) constaram que 13 das 155 amostras não cresceram a $42^{\circ} \mathrm{C}$, mas apresentaram coloração verde-escura, perfis esses sugestivos de C. dubliniensis. Testes moleculares (PCR) e (RAPD) aplicados a essas 13 amostras permitiram confirmar que 4 eram de C. dubliniensis, o que representava uma taxa de 2,8\% para aquele grupo estudado.

Estudo como o de Al Moisaid et al. (2001) mostra que não se pode descartar a importância das características morfológicas para a distinção entre $C$. dubliniensis e C. albicans. Estudando as características morfológicas das colônias e produção de clamidoconídios de 130 isolados de C. dubliniensis e 166 de C. albicans, e utilizando como meio de controle o agar-arroz-“Tween" e de diferenciação o Ágar Staib (AS) e 
Ágar citrato ácido-férrico caféico (CAF), esses autores constataram que todos os isolados de C. dubliniensis e C albicans produziram clamidoconídios quando cultivados no meio controle agar-arroz-“Tween”. Entretanto, nenhum isolado de $C$. albicans produziu clamidoconídios em AS ou CAF, ao contrário dos isolados de $C$. dubliniensis que cresceram nesses meios, $83,8 \%$ deles produzindo clamidoconídios. Todos os isolados de C. albicans se apresentavam lisos e brilhantes nos meios AS, após período de 48 e 72 horas de incubação a $30^{\circ} \mathrm{C}$, enquanto $97,7 \%$ C. dubliniensis apresentaram colônias ásperas com franjas e hifas. Testando a capacidade de crescimento de $C$. albicans e $C$. dubliniensis em meio de caldo de Sabouraud dextrose, acrescido com $6,5 \%$ de $\mathrm{NaCl}$, Alves et al. (2002) puderam identificar que dentre 266 isolados clínicos e 3 amostras como referência, 250 eram de C. albicans e 19 de C. dubliniensis. Todos os isolados de C. albicans cresceram nesse meio hipertônico até 96 horas, enquanto os de $C$. dubliniensis não apresentaram crescimento.

Tentativas para o levantamento de características fenotípicas e genotípicas que permitam diferenciar $C$. albicans e $C$. dubliniensis foram realizadas por Gutierrez et al. (2002), com a utilização de testes imunológicos, bioquímicos e enzimáticos, assim como de testes moleculares (PCR, RAPD) e cromogênicos. De acordo com Brandt et al. (2000), Willian e Lewis (2000), a utilização de biologia molecular e estudo do DNA são necessários frente à similaridade fenotípica entre essas duas espécies. 


\subsection{Terapias anti-retrovirais}

Com o surgimento de drogas anti-retrovirais potentes, e especialmente com o uso combinado entre elas, houve uma mudança no panorama da infecção pelo HIV. Esse recurso, geralmente constituído pela associação de dois inibidores da transcriptase reversa, ou de nucleosídeos análogos mais um inibidor da protease, produz acentuada redução da carga viral e aumento das células CD4, promovendo o decréscimo de infecções oportunistas e prolongamento da vida do paciente (HAMMER et al., 1997; MICHELET et al., 1998; PALLELA JR et al., 1998), bem como reduzindo o número de hospitalizações (MOUTON et al., 1997; TORRES; BARR, 1997).

Desde a introdução dos novos agentes anti-retrovirais, chamados de inibidores de protease (IP), a freqüência de candidose bucal tem decrescido em indivíduos infectados pelo HIV, ou mesmo com aids (DIZ DIOS et al., 2001; KORTING et al., 1999). Esses inibidores de protease agem diretamente na proteinase do HIV, tornando a enzima inativa e propiciando a formação de partículas virais não infectantes, fato que promove uma redução da carga viral e aumento de células CD4, restabelecendo a resposta imune (DEEKS et al., 1997).

A proteinase produzida pela $C$. albicans é da mesma classe da proteinase do HIV (HOEGL; OLLERT; KORTING, 1996). Com a utilização dos IP para o tratamento dos pacientes $\mathrm{HIV}+$, tem-se tornado rara a presença de candidose bucal e orofaringeana nesses pacientes (KORTING et al., 1999; VARGAS; JOLY, 2002). 
Experimentos in vitro do efeito de várias drogas inibidoras de protease tem permitido a redução de 30 a $85 \%$ nos níveis de atividade das proteinases fúngicas, usando-se concentrações da droga correspondentes às do nível sérico de pacientes em tratamentos (CASSONE et al., 1999; GRUBER et al, 1999; KORTING et al., 1999). De acordo com Culnane et al. (1999), Gortmaker et al. (2001), Louie et al. (2002), Palella et al. (1998), Palumbo et al. (1998) a terapia anti-retroviral causa redução do índice de infecções oportunistas e mortes em adultos e crianças com aids. 


\section{PROPOSIÇÃo}

1. Avaliar a prevalência de colonização e infecção bucal por Candida nessas crianças e relacionar com a carga viral, contagem CD4 e terapia anti-retroviral;

2. Identificar as espécies de Candida e respectivas freqüências na mucosa bucal;

3. Verificar, a partir dos métodos fenotípicos, crescimento a $42^{\circ} \mathrm{C}$ e coloração no meio CHROMagar, se em amostras identificadas pelo método tradicional como C. albicans não estaria ocorrendo a presença de C. dubliniensis;

4. Verificar a prevalência de cárie não-tratada em crianças com aids associando a fatores como condições sócio-demográficas, comportamentais e clínicas. 


\section{MATERIAL E MÉTODOS}

\subsection{Pacientes}

A casuística foi composta por 125 crianças com aids, examinadas no período de setembro de 2005 a outubro de 2006, com idade variando de 3 a 15 anos (média de idade 9,4 anos), diagnosticadas segundo critérios estabelecidos em 1994 pelo Centers for Disease Control and Prevention (CDC), Atlanta, GA, EUA. Cadastradas no ambulatório e leito-dia do Serviço de Infectologia do Instituto da Criança, Hospital das Clínicas, São Paulo, SP (ICr-HC/USP), sessenta e cinco delas eram do sexo feminino, 60 do sexo masculino, 56 brancos e 69 não-brancos, nascidas de mães soropositivas para o HIV. Embora a aids pediátrica seja considerada para crianças de 0 a 13 anos segundo o CDC, 1994, pacientes acima de 13 anos foram avaliados por estarem cadastrados no Serviço de Infectologia do ICr-HC/USP. O presente estudo foi aprovado pelos Comitês de Ética em Pesquisa das Instituições envolvidas (ICr-HC/USP (Anexo A) e Faculdade de Odontologia da Universidade de São Paulo - FO/USP) (Anexo B). A participação das crianças ocorreu mediante a assinatura do termo de consentimento livre e esclarecido pelos pais ou responsáveis legais (Anexo C).

O diagnóstico da infecção pelo HIV nessas crianças foi realizado através do teste sorológico ELISA (Enzyme Linked Immuno Sorbent Assay) pelo laboratório do ICr-HC/USP, utilizando o Kit COBAS CORE II, da Roche, fabricado em Mannheim, no Estado de Baden-Württemberg, Alemanha e consideradas infectadas pelo HIV 
aquelas que tivessem dois exames sorológicos positivos e confirmado com dois testes de carga viral (quantificação de RNA viral) que é realizado após 4 meses de idade. Estes testes são repetidos até os 18 meses de idade, em cujo período pode ocorrer soro-reversão.

Ao iniciar a coleta de dados, 9 das 125 crianças não estavam sob nenhum tipo de tratamento sistêmico ou tópico, enquanto as 116 crianças restantes faziam uso de TARV (terapia anti-retroviral), com as seguintes medicações: inibidores de protease (Amprenavir, Atazanavir, Indinavir, Lopinavir/Ritonavir, Nelfinavir, Tripanavir e Saquinavir), inibidores da transcriptase reversa análogos de nucleosídeo (Abacavir, Didanosina, Estavudina, Lamivudina, Tenofovir e Zidovudina) e inibidores da transcriptase reversa não-análogos de nucleosídeo (Efavirenz e Nevirapina). Trinta e quatro das 116 crianças também faziam uso de sulfametoxazol + trimetropina $\left(\right.$ Bactrin $^{\circledR}$ ) e/ou antibiótico adicionalmente à TARV.

\subsection{Dados clínicos e laboratoriais do paciente}

Para cada criança examinada, os dados referentes à história médica, uso de medicamentos, carga viral e contagem CD4 foram obtidos dos respectivos prontuários médicos e anotados em ficha clínica apropriada (Anexo D). Esses dados foram registrados de acordo com os critérios do sistema de classificação para crianças HIV+/aids.

A avaliação do uso de medicamentos refere-se ao uso contínuo de TARV e/ou antimicrobianos. Uma avaliação em separado considerou as crianças que não 
eram tratadas com remédios em forma de cápsulas e faziam uso contínuo de medicamentos contendo açúcar em sua composição.

A carga viral foi determinada através de teste de amplificação de ácidos nucléicos para a quantificação do RNA plasmático do HIV-1 através do método AMPLICOR HIV-1 MONITOR® Test, v1.5 (Roche Diagnosis Molecular, Pleasant, CA, USA). O limite de detecção do método é > 400 cópias $/ \mathrm{ml}$. Valores acima de 100.000 cóp/ml são indicadores de piora clínica do paciente. A quantificação de linfócitos T CD3+, CD4+ e CD8+ foi realizada com o auxílio do citômetro de fluxo FACSCalibur (B\&D, San Jose, CA, EUA), foram utilizados os anticorpos monoclonais (AcMo) conjugados a compostos fluorescentes (Triest - B\&D Imunocytometry Systems, San Jose-CA, EUA). Foi considerada evidência de supressão imunológica moderada ou severa para valores abaixo de 1000 céls $/ \mathrm{mm}^{3}$ para a faixa etária de 1 a 5 anos, de 500 céls $/ \mathrm{mm}^{3}$ para a faixa de 6 a 12 anos, e de 350 céls $/ \mathrm{mm}^{3}$ para 13 anos ou mais (CENTERS FOR DISEASE CONTROL AND PREVENTION, 1994). Os exames foram realizados, respectivamente, no Setor de Biologia Molecular e Setor de Imunologia do Laboratório Central do Hospital das Clínicas da Faculdade de Medicina da USP.

\subsection{Método de coleta, transporte e processamento das amostras de mucosa bucal}

De cada paciente, amostras de raspados da superfície de mucosa bucal normal, e da superfície da lesão quando era sugestiva de candidose foram coletados 
com auxílio de cytobrush estéril através de movimentos circulares. As amostras foram colocadas em tubos de ensaio separados contendo em cada um $5 \mathrm{ml}$ de salina estéril a $0,85 \%$ de $\mathrm{NaCl}$ e transportadas para o Laboratório de Micologia do Instituto de Medicina Tropical da Universidade de São Paulo (IMT-USP), onde foram centrifugadas por 10 minutos a 1000 rpm e o sobrenadante desprezado.

\subsection{Exame direto a fresco}

Uma amostra do material sedimentado em cada tubo foi dispersa separadamente sobre lâminas com auxílio de alça estéril e cobertas com lamínulas. Cada preparação foi realizada em duplicata. O exame direto a fresco foi realizado sob microscopia óptica com objetivas de 10 e 40x nas quatro preparações, e o resultado considerado positivo mediante a presença de pseudo-hifas e/ou blastoconídios de levedura.

\subsection{Cultura da amostra}

O sedimento restante nos tubos de ensaio foi semeado em tubo contendo ágar Sabouraud dextrose (Difco, Detroit, EUA) com 0,1\% de cloranfenicol para cultura de leveduras. A cultura foi positiva quando houve crescimento no plaqueamento em ágar. Subseqüentemente, as culturas positivas foram semeadas 
em CHROMagar (CHROMagar ${ }^{\mathrm{tm}}$ Candida, Paris, França) para testar a pureza da amostra.

\subsection{Identificação das leveduras}

As leveduras presentes nas culturas positivas foram identificadas nos Laboratórios de Micologia do IMT-USP e de Micologia do Instituto de Ciências Biomédicas da Universidade de São Paulo (ICB-USP). A identificação foi realizada segundo as características macroscópicas, reprodutivas e fisiológicas das leveduras, de acordo com as técnicas do Manual "The Yeasts", de Kurtzman e Fell (1998) e anotados em ficha apropriada (Anexo E).

\subsection{Diferenciação das espécies C. albicans e C. dubliniensis por testes fenotípicos}

Para os testes fenotípicos, visando a diferenciação entre C. albicans e $C$. dubliniensis, foram utilizados C. albicans (ATCC 64548) e C. dubliniensis (ATCC 777) como controle positivo. 


\subsubsection{Teste cromogênico}

Todas as amostras de C. albicans, previamente identificadas pelos métodos tradicionais, foram semeadas em meio cromogênico (CHROMagar - CHROMagar ${ }^{\mathrm{tm}}$ Cândida, Paris, França ) e incubadas a $37^{\circ} \mathrm{C}$ por 48 horas. Neste meio CHROMagar, colônias de C. albicans apresentam coloração verde-claro e de C. dubliniensis verde-escuro.

4.7.2 Método de "crescimento a $42^{\circ} \mathrm{C}$ " (SULLIVAN et al.,1995)

Colônias, com 24 horas de crescimento, de C. albicans foram semeadas em 2 tubos de ensaio contendo ágar Sabouraud-dextrose (Difco, Detroit, Michigan, EUA) sendo um tubo incubado a $37^{\circ} \mathrm{C}$ e o outro a $42^{\circ} \mathrm{C}$ por 72 horas. Colônias de $\mathrm{C}$. albicans crescem tanto a $37^{\circ} \mathrm{C}$ como a $42^{\circ} \mathrm{C}$, enquanto $\mathrm{C}$ dubliniensis somente a $37^{\circ} \mathrm{C}$.

\subsection{Prevalência de cárie e aspectos clínicos da mucosa bucal}

O exame para prevalência de cárie obedeceu aos critérios estabelecidos pela Organização Mundial de Saúde (OMS, 1996) para levantamentos de saúde 
bucal (WORLD HEALTH ORGANIZATION, 1997). Para a realização desse exame foi necessário o uso de espelho plano e sonda periodontal (CPI). Uma única cirurgiãdentista, treinada e calibrada para essa finalidade, realizou todos os exames, sendo assistida por uma aluna de graduação em Odontologia da FO-USP, na condição de anotadora do levantamento. A avaliação de reprodutibilidade intra-observadores envolveu o reexame de 1/10 da amostra, e aplicação do teste estatístico Kappa, cujo resultado foi considerado satisfatório para esse tipo de avaliação $(0,84)$. A prevalência de cárie dentária nas dentições decídua e permanente foi estimada através dos índices ceo-d e CPO-D (WORLD HEALTH ORGANIZATION, 1997, 1997), respectivamente. Foram consideradas com necessidades de tratamento odontológico as crianças que apresentaram ao menos um dente decíduo ou permanente afetado por cárie e ainda não tratado. Concomitantemente, a mucosa bucal foi examinada, e nos casos em que algum tipo de lesão foi observada, o respectivo diagnóstico e tratamento foram providenciados ao paciente.

\subsection{Dados sócio-demográficos e comportamentais}

Entrevista realizada com os responsáveis pelas crianças permitiu o levantamento de dados quanto as condições sociodemográficas (renda familiar e escolaridade do responsável legal) e características do domicílio (casa própria ou outra condição de moradia, aglomeração domiciliar) (Anexo F).

As características comportamentais registradas incluem hábitos alimentares com foco na freqüência de consumo de açúcar e refrigerantes; higiene bucal (escovação e uso de fio dental); freqüência de consultas ao dentista; e percepção do 
responsável quanto à saúde bucal da criança (Anexo F), da mesma ficha extraíramse informações sobre o sexo, idade e grupo étnico das crianças.

\subsection{Análise estatística}

A análise estatística utilizou o programa Stata 8.0, 2003. Ambos os desfechos do estudo - prevalência de cultura positiva para Candida spp. E de cárie não-tratada - foram avaliados quanto à sua associação com características socioeconômicas, aspectos comportamentais e fatores clínicos dos pacientes. Para essa finalidade, foi utilizada análise de regressão de Poisson (BARROS; HIRATA, 2003), com controle por idade.

Cada variável independente foi avaliada isoladamente no modelo de regressão, resultando a razão de prevalências, nível de significância (valor de $P$ ) e seu respectivo intervalo de confiança (95\%), como medidas de associação. A análise de regressão de Poisson também permitiu o delineamento de modelos multivariados, também controlados por idade, para ambos os desfechos. Para essa finalidade, seguiu-se o procedimento "backward" (retroativo), com $P<0,25$ como critério para inclusão no modelo inicial e $P<0,05$ para manutenção no modelo final. 


\section{RESULTADOS}

\subsection{Manifestações bucais}

O exame clínico da mucosa bucal das 125 crianças mostrou que $12 \%$ (15/125) delas apresentavam algum tipo de lesão bucal. A lesão mais encontrada foi a candidose bucal (7 casos eram de candidose pseudomembranosa e 1 caso de candidose eritematosa), seguida por 1 caso de fibromatose gengival; 2 casos de herpes labial; 2 casos de afta minor em fundo de sulco maxila esquerda e 2 úlceras traumáticas em mucosa jugal.

\subsection{Colonização bucal por Candida spp.}

Coleta microbiológica para verificação de colonização bucal por Candida spp. foi realizada em 117 pacientes. Considerando que pacientes com candidose bucal tiveram duas a três amostras coletadas, uma da lesão e outras das áreas remanescentes clinicamente normais da mucosa bucal, um total de 124 amostras foi coletada, envolvendo os seguintes sítios: 117 de toda extensão da mucosa bucal, 3 da lateral da língua e 4 do palato mole. $O$ exame direto a fresco e cultura das amostras foi realizado e analisado. O exame direto a fresco foi positivo em 32 
amostras das 124 obtidas e a cultura mostrou positividade para colonização por Candida em 86 amostras do total.

Todas as associações e o modelo multivariado foram ajustados por idade. A Tabela 5.1 mostra a associação de cultura positiva e características sóciodemográficas das crianças. Foi identificada maior prevalência de colonização bucal por Candida em crianças que não moram em casas próprias $(P=0,003)$ e tinham mais de dois irmãos $(P=0,019)$.

Tabela 5.1 - Associação entre cultura positiva e características sócio-demográficas de crianças com aids assistidas no ICr/HC - USP, 2006

\begin{tabular}{|c|c|c|c|c|}
\hline Características & Categorias & $\begin{array}{l}\text { Cultura } \\
\text { Negativa }\end{array}$ & $\begin{array}{l}\text { Cultura } \\
\text { Positiva }\end{array}$ & $\begin{array}{l}\text { RP* (IC 95\%) } \\
\text { Significância }\end{array}$ \\
\hline \multicolumn{5}{|c|}{ Sócio-demográficas } \\
\hline \multirow[t]{2}{*}{ Sexo } & Feminino & 29 & 34 & $1,16(0,85-1,58)$ \\
\hline & Masculino & 20 & 34 & $P=0,361$ \\
\hline \multirow[t]{2}{*}{ Grupo étnico } & Negros & 31 & 42 & $0,96(0,70-1,32)$ \\
\hline & Brancos & 18 & 26 & $P=0,810$ \\
\hline \multirow[t]{2}{*}{ Escolaridade do responsável } & $<11$ anos & 34 & 54 & $0,78(0,51-1,18)$ \\
\hline & $\geq 11$ anos & 15 & 14 & $P=0,234$ \\
\hline \multirow{3}{*}{ Renda familiar } & $<2$ sal. min. (a) & 26 & 39 & $0,92(0,67-1,26)$ \\
\hline & $\geq 2$ sal. min. (a) & 23 & 29 & $P=0,605$ \\
\hline & Domicílio & & & \\
\hline \multirow[t]{2}{*}{ Casa própria } & Sim & 36 & 32 & $0,63(0,46-0,86)$ \\
\hline & Não & 13 & 36 & $P=0,003$ \\
\hline \multirow[t]{2}{*}{ Irmãos } & 2 ou mais & 10 & 26 & $1,42(1,06-1,90)$ \\
\hline & 0 ou 1 & 39 & 42 & $P=0,019$ \\
\hline \multirow[t]{2}{*}{ Aglomeração domiciliar } & $\geq 1 \mathrm{hab} / \mathrm{com}$ & 17 & 25 & $1,05(0,76-1,45)$ \\
\hline & $<1 \mathrm{hab} / \mathrm{com}$ & 32 & 43 & $P=0,757$ \\
\hline
\end{tabular}

${ }^{*}$ RP: razão de prevalência ajustado pela idade.

(a) salário mínimo brasileiro, $\mathrm{R} \$ 380,00$.

Em relação às características comportamentais das crianças, a Tabela 5.2 mostra que crianças com maior necessidade de tratamentos de restauração dentária possuem prevalência mais elevada em $86 \%$ de colonização bucal por Candida (intervalo de confiança de $95 \%$ de $28 \%$ a $169 \%$ ) do que aquelas sem necessidade de tratamento dentário. Crianças cujos cuidadores avaliaram sua condição bucal como boa ou muito boa tinham $42 \%$ menos prevalência de cultura positiva. 
Tabela 5.2 - Associação entre cultura positiva e característica comportamental de crianças com aids assistidas no $\mathrm{ICr} / \mathrm{HC}$ - USP, 2006

\begin{tabular}{|c|c|c|c|c|}
\hline Características & Categorias & $\begin{array}{l}\text { Cultura } \\
\text { Negativa }\end{array}$ & $\begin{array}{l}\text { Cultura } \\
\text { Positiva }\end{array}$ & $\begin{array}{l}\text { RP* (IC 95\%) } \\
\text { Significância }\end{array}$ \\
\hline \multicolumn{5}{|c|}{ Cuidados de saúde bucal } \\
\hline Consulta ao dentista & $\begin{array}{l}\geq 4 \text { vezes } \\
<4 \text { vezes }\end{array}$ & $\begin{array}{l}26 \\
23\end{array}$ & $\begin{array}{l}42 \\
26\end{array}$ & $\begin{array}{c}1,14(0,81-1,62) \\
P=0,454\end{array}$ \\
\hline Escovação diária & $\begin{array}{l}\geq 3 \text { vezes } \\
<3 \text { vezes }\end{array}$ & $\begin{array}{l}24 \\
25\end{array}$ & $\begin{array}{l}24 \\
44\end{array}$ & $\begin{array}{c}0,79(0,56-1,10) \\
P=0,159\end{array}$ \\
\hline Fio dental (diário) & $\operatorname{Sim}_{\text {Não }}$ & $\begin{array}{l}16 \\
33\end{array}$ & $\begin{array}{l}12 \\
56\end{array}$ & $\begin{array}{c}0,68(0,42-1,08) \\
P=0,100\end{array}$ \\
\hline Necessidade de tratamento & $\begin{array}{l}\text { Sim } \\
\text { Não }\end{array}$ & $\begin{array}{l}21 \\
28\end{array}$ & $\begin{array}{l}41 \\
27\end{array}$ & $\begin{array}{c}1,86(1,28-2,69) \\
P=0,001\end{array}$ \\
\hline \multicolumn{5}{|c|}{ Hábitos alimentares } \\
\hline Açúcar (freqüência diária) & $\begin{array}{l}\geq 3 \text { vezes } \\
<3 \text { vezes }\end{array}$ & $\begin{array}{c}4 \\
45\end{array}$ & $\begin{array}{l}14 \\
54\end{array}$ & $\begin{array}{c}1,34(0,96-1,85) \\
P=0,084\end{array}$ \\
\hline Refrigerante (por dia) & $\begin{array}{l}\geq 1 \mathrm{vez} \\
<1 \mathrm{vez}\end{array}$ & $\begin{array}{l}14 \\
35\end{array}$ & $\begin{array}{l}16 \\
52\end{array}$ & $\begin{array}{c}0,90(0,61-1,32) \\
P=0,591\end{array}$ \\
\hline \multicolumn{5}{|c|}{ Percepção de saúde bucal } \\
\hline Avaliação do cuidador & $\begin{array}{l}\text { Boa, muito boa } \\
\text { Regular, ruim }\end{array}$ & $\begin{array}{l}32 \\
17 \\
\end{array}$ & $\begin{array}{l}23 \\
45 \\
\end{array}$ & $\begin{array}{c}0,58(0,41-0,82) \\
P=0,002\end{array}$ \\
\hline
\end{tabular}

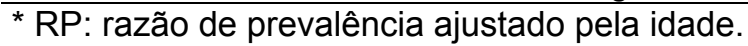

De acordo com a Tabela 5.3, a condição clínica das crianças não associou significantemente com a cultura positiva, mas houve associação entre algumas condições de uso contínuo de medicamentos. A prevalência de cultura positiva foi $37 \%$ menor para as crianças que faziam uso de medicação anti-retroviral do tipo inibidor da transcriptase reversa análogo de nucleosídio (ITRN). As crianças que faziam uso de medicação antimicrobiana (antibióticos e/ou sulfametoxazol + trimetropina) mostraram-se mais susceptíveis à colonização bucal por Candida. 
Tabela 5.3 -Associação entre cultura positiva, condição clínica e uso contínuo de medicamento em crianças com aids assistidas no ICr/HC - USP, 2006

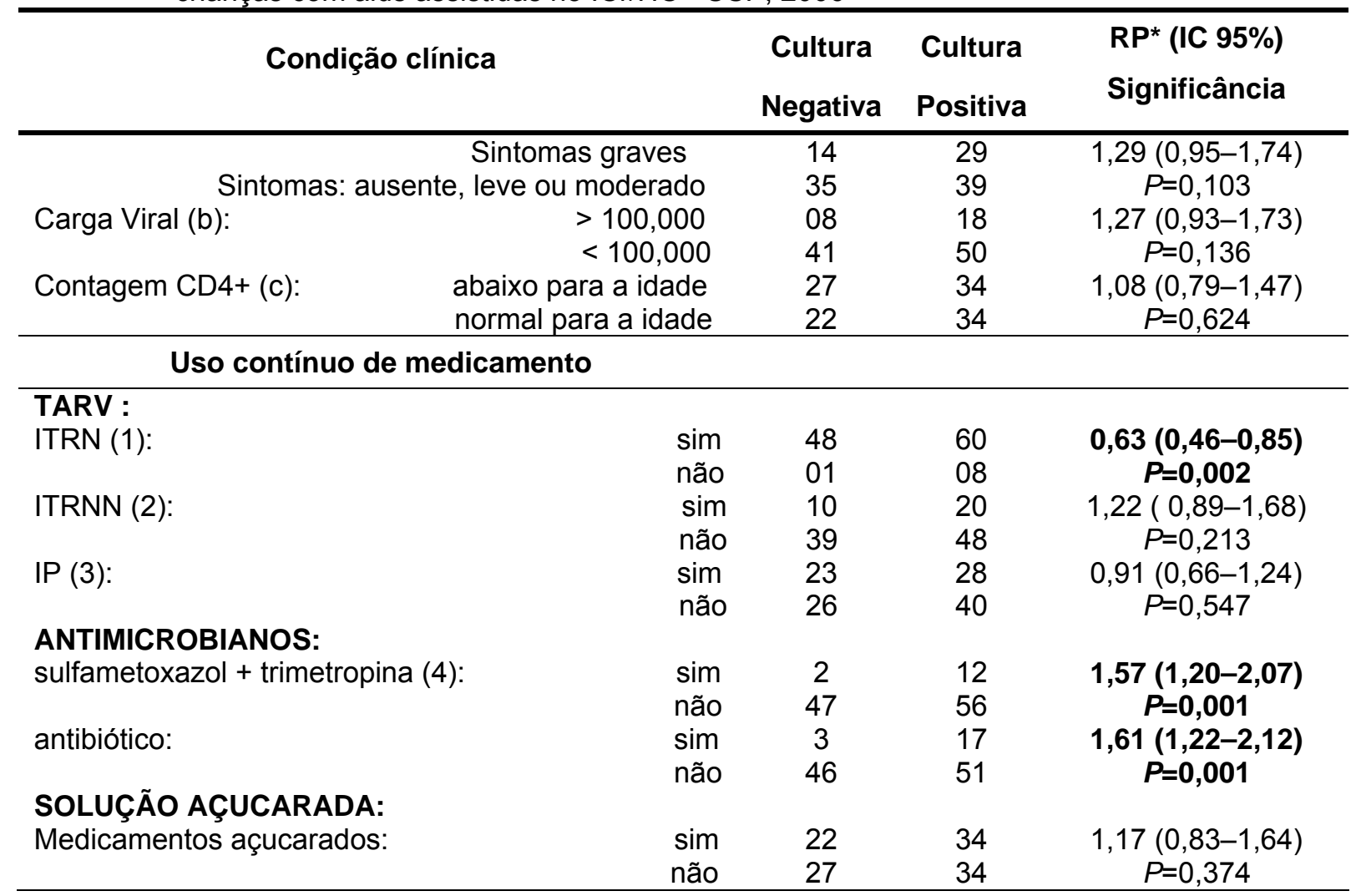

${ }^{*}$ RP: razão de prevalência ajustado pela idade.
(a) Cópias de RNA HIV por milímetro de plasma.
(b) Células linfócitos T CD4 + por milímetro cúbico de sangue.
(1)ITRN= inibidor da transcriptase reversa análogo de nucleosídeo.
(2)ITRNN= inibidor da transcriptase reversa não-análogo de nucleosídeo.
(3)IP= inibidor de protease.
(4) sulfametoxazol + trimetropina: Bactrim ${ }^{\circledR}$.

A Tabela 5.4 indica que as crianças que não faziam uso de nenhuma medicação anti-retroviral tiveram 96\% mais prevalência de cultura positiva para Candida que as crianças que recebiam ITRN.

Tabela 5.4 -Associação entre cultura positiva e uso combinado de TARV em crianças com aids assistidas no $\mathrm{ICr} / \mathrm{HC}$ - USP, 2006

\begin{tabular}{lcccc}
\hline Uso combinado de TARV & $\begin{array}{c}\text { Cultura } \\
\text { Negativa }\end{array}$ & $\begin{array}{c}\text { Cultura } \\
\text { Positiva }\end{array}$ & $\begin{array}{c}\mathbf{R}_{\mathbf{3}} \text { Prev }^{*} \text { (IC 95\%) } \\
\text { significância }\end{array}$ & valor- $\boldsymbol{P}$ \\
\hline ITRN (1) & 18 & 15 & referência & \\
ITRN(1) + ITRNN(2) & 10 & 20 & $1,49(0,95-2,33)$ & 0,085 \\
ITRN(1) + IP (3) & 20 & 25 & $1,22(0,78-1,93)$ & 0,383 \\
Nenhum & 01 & 08 & $1,96(1,25-3,08)$ & $\mathbf{0 , 0 0 4}$ \\
\hline
\end{tabular}

${ }^{*}$ RP: razão de prevalência ajustada pela idade.

(1)ITRN= inibidor da transcriptase reversa análogo de nucleosídeo.

(2)ITRNN= inibidor da transcriptase reversa não-análogo de nucleosídeo.

(3) $I \mathrm{P}=$ inibidor de protease. 
As crianças que apresentaram algum tipo de lesão bucal (candidose pseudomembranosa ou eritematosa, fibromatose gengival, herpes, afta ou úlcera traumática) e que tiveram exame direto a fresco positivo também apresentaram maior prevalência de cultura positiva para Candida (Tabela 5.5).

Tabela 5.5 -Fatores associados na cultura positiva em crianças com aids assistidas no ICr/HC - USP, 2006

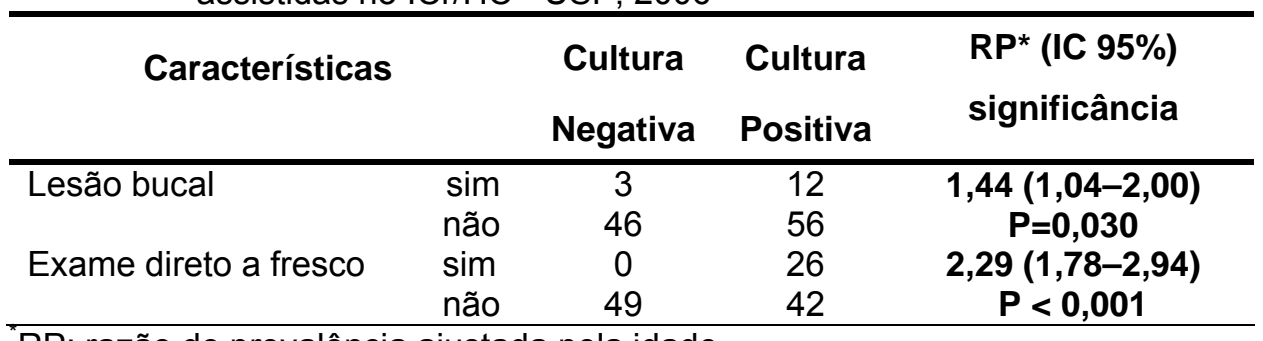

RP: razão de prevalência ajustada pela idade.

A avaliação multivariada das variáveis independentes, com ajuste por idade, incluiu condições sócio-demográficas (casa própria), comportamentais (necessidade de tratamento de restauração dentária) e características clínicas (uso de ITRN e antimicrobianos) significantemente associadas com o resultado de cultura positiva para Candida. O modelo selecionado explicou a variação de $38 \%$ da variável de desfecho (cultura positiva) e identificou corretamente $78 \%$ das crianças com cultura negativa (Tabela 5.6). 
Tabela 5.6 - Associação multivariada entre cultura positiva e características das crianças com aids assistidas no $\mathrm{ICr} / \mathrm{HC}$ - USP, 2006

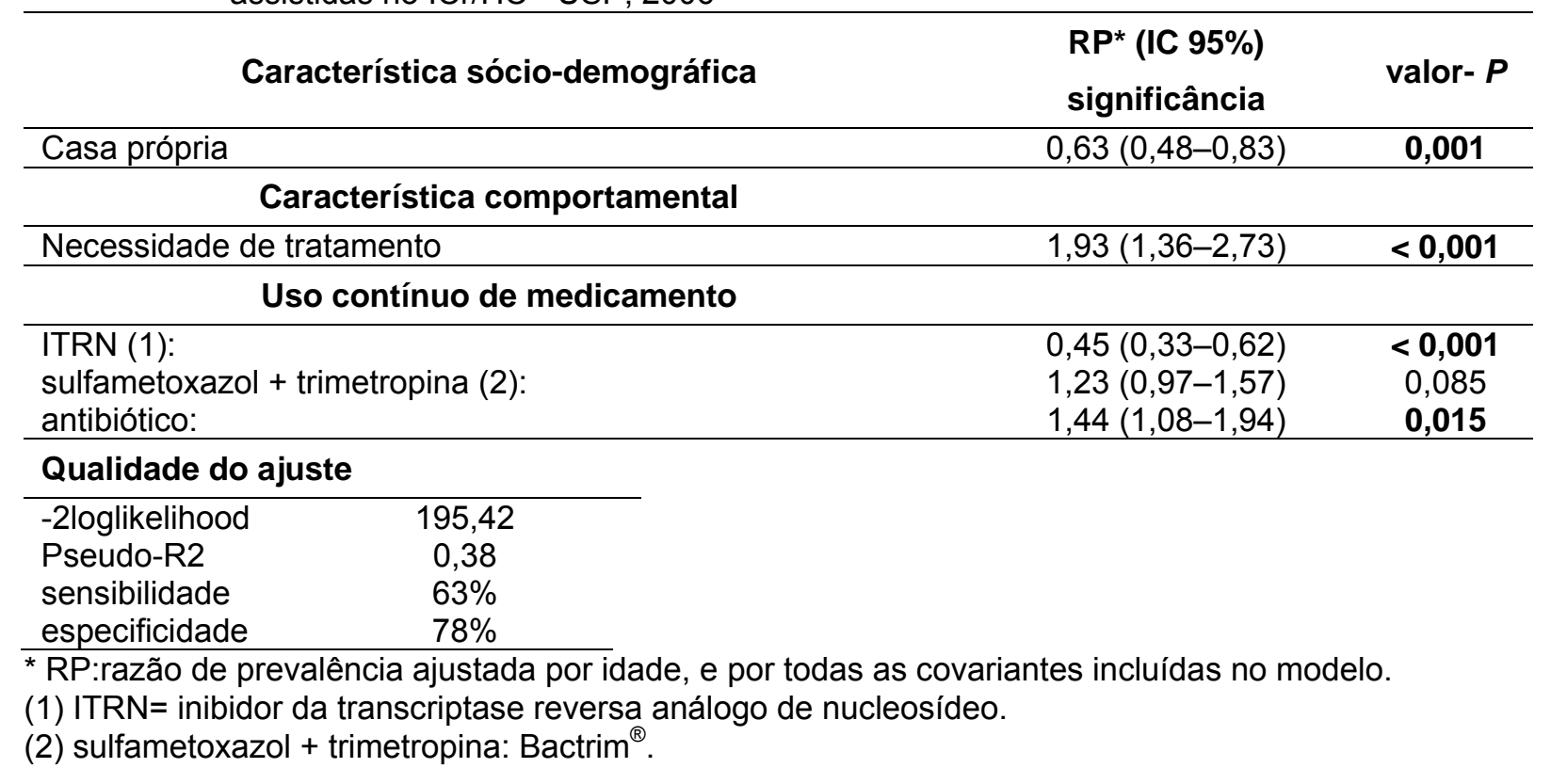

\subsection{Identificação das leveduras isoladas}

Das 86 amostras de leveduras isoladas, a espécie mais freqüente foi $C$. albicans (69/86) seguido por C. tropicalis (5/86), C. kefyr (4/86), C. krusei (3/86), C. glabrata (2/86), C. guilliermondii (1/86), e duas amostras não identificadas por apresentarem crescimento fastidioso. A freqüência das diferentes espécies de Candida isoladas da mucosa bucal de pacientes com aids é mostrada na Figura 5.1. 


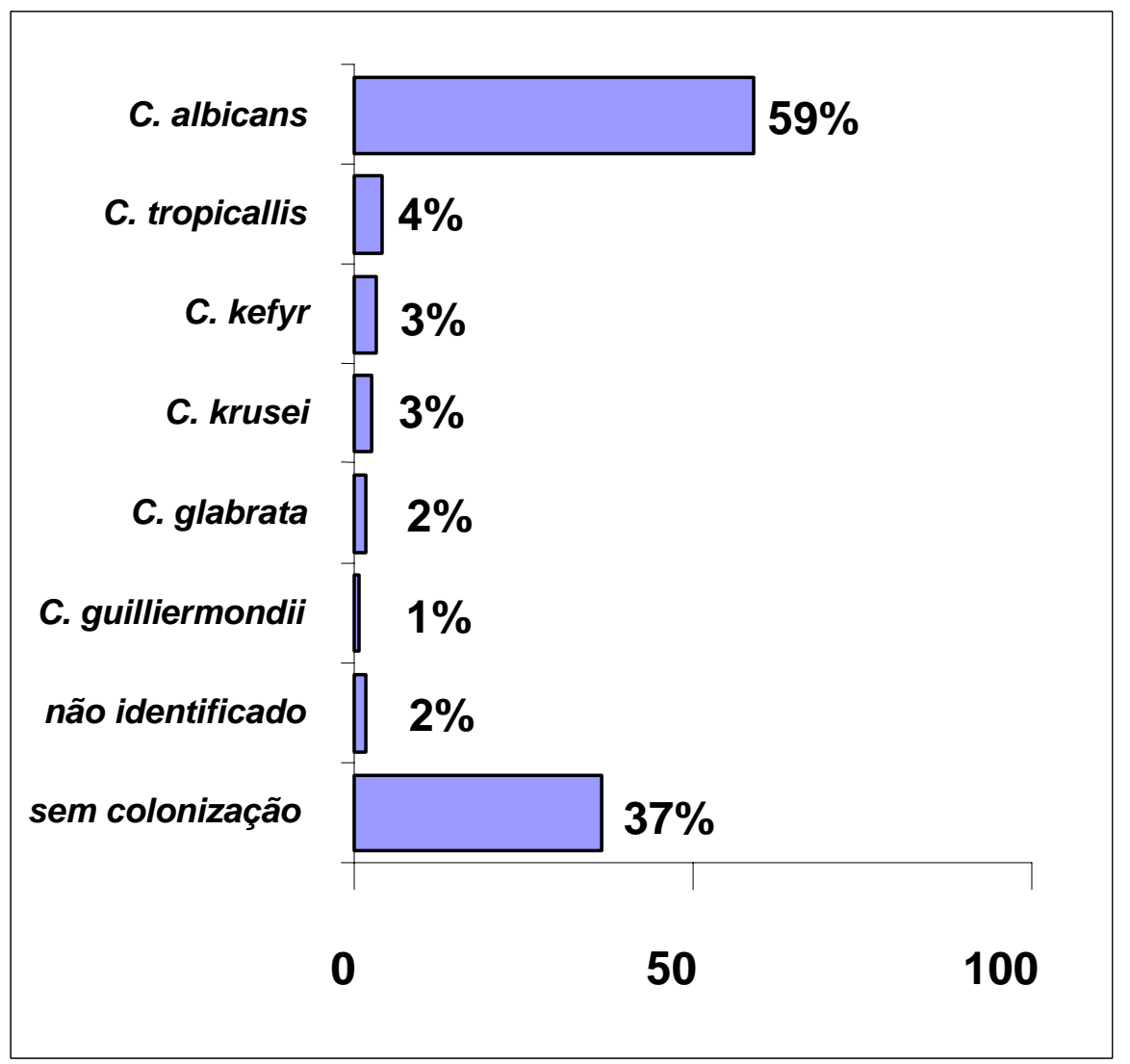

Figura 5.1 - Prevalência das espécies de Candida isoladas da mucosa bucal de crianças com aids assistidas no $\mathrm{ICr} / \mathrm{HC}$ - USP, 2006

\subsection{Testes fenotípicos utilizados para diferenciação de C. dubliniensis entre amostras identificadas como C. albicans}

Sessenta e nove amostras identificadas inicialmente pelo método tradicional como C. albicans foram avaliadas quanto ao seu crescimento a $42^{\circ} \mathrm{C}$ e cultivadas em meio cromogênico para uma triagem de identificação de C. dubliniensis. Destas amostras, 14 apresentaram coloração verde-escuro, sugestivo de C. dubliniensis, entretanto, no teste de termotolerância todas as amostras cresceram a $42^{\circ} \mathrm{C}$, sugestivo de C. albicans. 


\subsection{Prevalência de cárie}

A prevalência de cárie não-tratada foi de $58 \%$ nas crianças com aids examinadas. A razão específica para a idade foi mais elevada para crianças com dentição decídua e mista, 68\% para 3 a 6 anos, e 67\% para 7 a 10 anos (Figura 5.2). Do total das crianças com menos de 10 anos de idade que tinham ao menos um dente afetado por cárie, $40 \%$ delas nunca haviam recebido nenhum tratamento dentário.

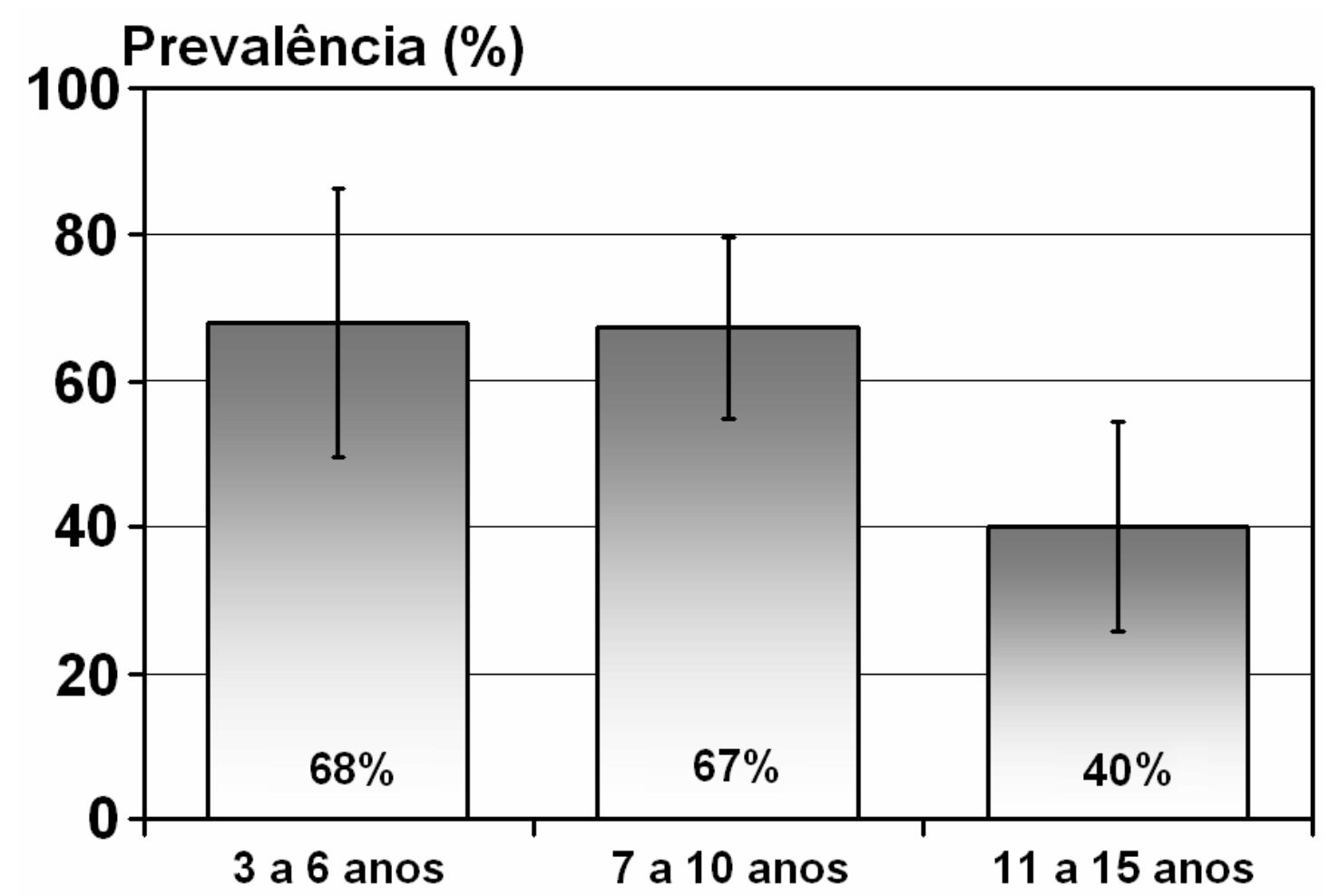

Figura 5.2 - Prevalência (intervalo de confiança 95\%) de necessidade de tratamento em crianças com aids assistidas no ICr/HC - USP, 2006

A Tabela 5.7 descreve a prevalência de cárie não-tratada de modo associado a características sócio-demográficas de interesse. Pacientes cuja renda familiar era inferior a 2 salários mínimos tiveram maior necessidade de tratamento odontológico $(P<0,01)$. A prevalência de cárie também foi significantemente mais 
expressiva $(P<0,01)$ em crianças que tinham mais de dois irmãos, residiam em domicílios mais aglomerados, e cujos cuidadores possuiam menor grau de escolaridade.

Tabela 5.7 - Associação entre a prevalência de cáries não-tratadas e características sóciodemográficas de crianças com aids assistidas no ICr/HC - USP, 2006

\begin{tabular}{|c|c|c|c|c|}
\hline Características & Categorias & $\begin{array}{l}\text { Ausência } \\
\text { de cárie }\end{array}$ & $\begin{array}{l}\text { Presença } \\
\text { de cárie }\end{array}$ & $\begin{array}{l}\text { RP* (IC 95\%) } \\
\text { significância }\end{array}$ \\
\hline \multicolumn{5}{|c|}{ Sócio-demográficas } \\
\hline Sexo & $\begin{array}{l}\text { masculino } \\
\text { feminino }\end{array}$ & $\begin{array}{l}23 \\
30\end{array}$ & $\begin{array}{l}37 \\
35\end{array}$ & $\begin{array}{c}1,21(0,90-1,64) \\
P=0,204\end{array}$ \\
\hline Grupo étnico & $\begin{array}{l}\text { negros } \\
\text { brancos }\end{array}$ & $\begin{array}{l}33 \\
20\end{array}$ & $\begin{array}{l}47 \\
25\end{array}$ & $\begin{array}{c}1,08(0,79-1,49) \\
P=0,627\end{array}$ \\
\hline Escolaridade do cuidador & $\begin{array}{l}\geq 11 \text { anos } \\
<11 \text { anos }\end{array}$ & $\begin{array}{l}22 \\
31\end{array}$ & $\begin{array}{l}10 \\
62\end{array}$ & $\begin{array}{c}0,48(0,28-0,82) \\
P=0,007\end{array}$ \\
\hline Renda familiar & $\begin{array}{l}>2 \text { sal } \min (a) \\
\leq 2 \text { sal.min }(a)\end{array}$ & $\begin{array}{l}31 \\
22 \\
\end{array}$ & $\begin{array}{l}15 \\
57 \\
\end{array}$ & $\begin{array}{c}0,46(0,30-0,72) \\
P=0,001\end{array}$ \\
\hline & Domicílio & & & \\
\hline $\begin{array}{l}\text { Irmãos } \\
\text { Aglomeração domiciliar }\end{array}$ & $\begin{array}{c}3 \text { ou mais } \\
0 \text { a } 2 \\
\geq 1 \text { hab/côm } \\
<1 \text { hab/côm } \\
\end{array}$ & $\begin{array}{l}10 \\
43 \\
22 \\
31 \\
\end{array}$ & $\begin{array}{l}29 \\
43 \\
51 \\
21\end{array}$ & $\begin{array}{c}1,46(1,10-1,93) \\
P=0,008 \\
1,68(1,16-2,43) \\
P=0,006\end{array}$ \\
\hline
\end{tabular}

* RP: razão de prevalência ajustado pela idade.

(a) salário mínimo brasileiro no período da pesquisa, $R \$ 380,00$.

A associação da prevalência de cárie não-tratada com características comportamentais relacionados a hábitos alimentares e cuidados de saúde bucal (Tabela 5.8) demonstrou que a alta freqüência na ingestão de açúcar foi considerada deletéria $(P=0,03)$, enquanto escovação dentária com freqüência diária de três ou mais vezes $(P=0,07)$ e uso diário de fio dental foram indicados como fatores de proteção $(P=0,02)$. 
Tabela 5.8 - Associação entre a prevalência de cárie não-tratada e característica comportamental de crianças com aids assistidas no ICr/HC - USP, 2006

\begin{tabular}{|c|c|c|c|c|}
\hline Características & Categorias & $\begin{array}{c}\text { Ausência } \\
\text { de cárie }\end{array}$ & $\begin{array}{l}\text { Presença } \\
\text { de cárie }\end{array}$ & $\begin{array}{l}\text { RP* (IC 95\%) } \\
\text { significância }\end{array}$ \\
\hline \multicolumn{5}{|c|}{ Cuidados de saúde bucal } \\
\hline Consulta ao dentista & $\begin{array}{l}\geq 4 \text { vezes } \\
<4 \text { vezes }\end{array}$ & $\begin{array}{l}34 \\
19\end{array}$ & $\begin{array}{l}38 \\
34\end{array}$ & $\begin{array}{c}0,89(0,65-1,23) \\
P=0,483\end{array}$ \\
\hline Escovação diária & $\begin{array}{l}\geq 3 \text { vezes } \\
<3 \text { vezes }\end{array}$ & $\begin{array}{l}27 \\
26\end{array}$ & $\begin{array}{l}25 \\
47\end{array}$ & $\begin{array}{c}0,74(0,53-1,03) \\
P=0,074\end{array}$ \\
\hline Fio dental (diário) & $\begin{array}{l}\text { sim } \\
\text { não }\end{array}$ & $\begin{array}{l}19 \\
34\end{array}$ & $\begin{array}{l}10 \\
62\end{array}$ & $\begin{array}{c}0,54(0,32-0,91) \\
P=0,021\end{array}$ \\
\hline Colutório & $\begin{array}{l}\text { sim } \\
\text { não }\end{array}$ & $\begin{array}{l}10 \\
43 \\
\end{array}$ & $\begin{array}{c}7 \\
65 \\
\end{array}$ & $\begin{array}{c}0,71(0,39-1,29) \\
P=0,258\end{array}$ \\
\hline \multicolumn{5}{|c|}{ Hábitos alimentares } \\
\hline Açúcar (freqüência diária) & $\begin{array}{l}\geq 3 \text { vezes } \\
<3 \text { vezes }\end{array}$ & $\begin{array}{l}23 \\
30\end{array}$ & $\begin{array}{l}43 \\
29\end{array}$ & $\begin{array}{c}1,42(1,03-1,94) \\
P=0,030\end{array}$ \\
\hline Refrigerante (por dia) & $\begin{array}{l}\geq 1 \text { vez } \\
<1 \text { vez }\end{array}$ & $\begin{array}{l}12 \\
41\end{array}$ & $\begin{array}{l}22 \\
50\end{array}$ & $\begin{array}{c}1,16(0,85-1,58) \\
P=0,341\end{array}$ \\
\hline
\end{tabular}

${ }^{*}$ RP: razão de prevalência ajustado pela idade.

A Tabela 5.9 mostra a distribuição de prevalência de cárie não-tratada segundo condições clínicas dos pacientes e uso contínuo de medicamentos. Indicadores de estágio clínico mais avançado da doença aids associaram significantemente com prevalência mais elevada de cárie não-tratada. Esta condição foi $48 \%(11 \%$ a $98 \%$, intervalo de confiança $95 \%)$ mais prevalente para crianças com sintomatologia severa que para pacientes assintomáticos ou com sintomas leve e moderado da aids; e $58 \%$ (19\% a 109\%, IC 95\%) mais prevalente para crianças com carga viral acima de 100.000 cóp $/ \mathrm{ml}$. Cerca de metade das crianças fazia uso contínuo de medicamentos açucarados. Entretanto, as três variáveis relacionadas ao uso contínuo de medicamentos não tiveram associação significante com condição dentária na amostra estudada $(P<0,05)$. 
Tabela 5.9 - Associação entre a prevalência de cárie não-tratada, condição clínica e uso contínuo de medicamento em crianças com aids assistidas no ICr/HC - USP, 2006

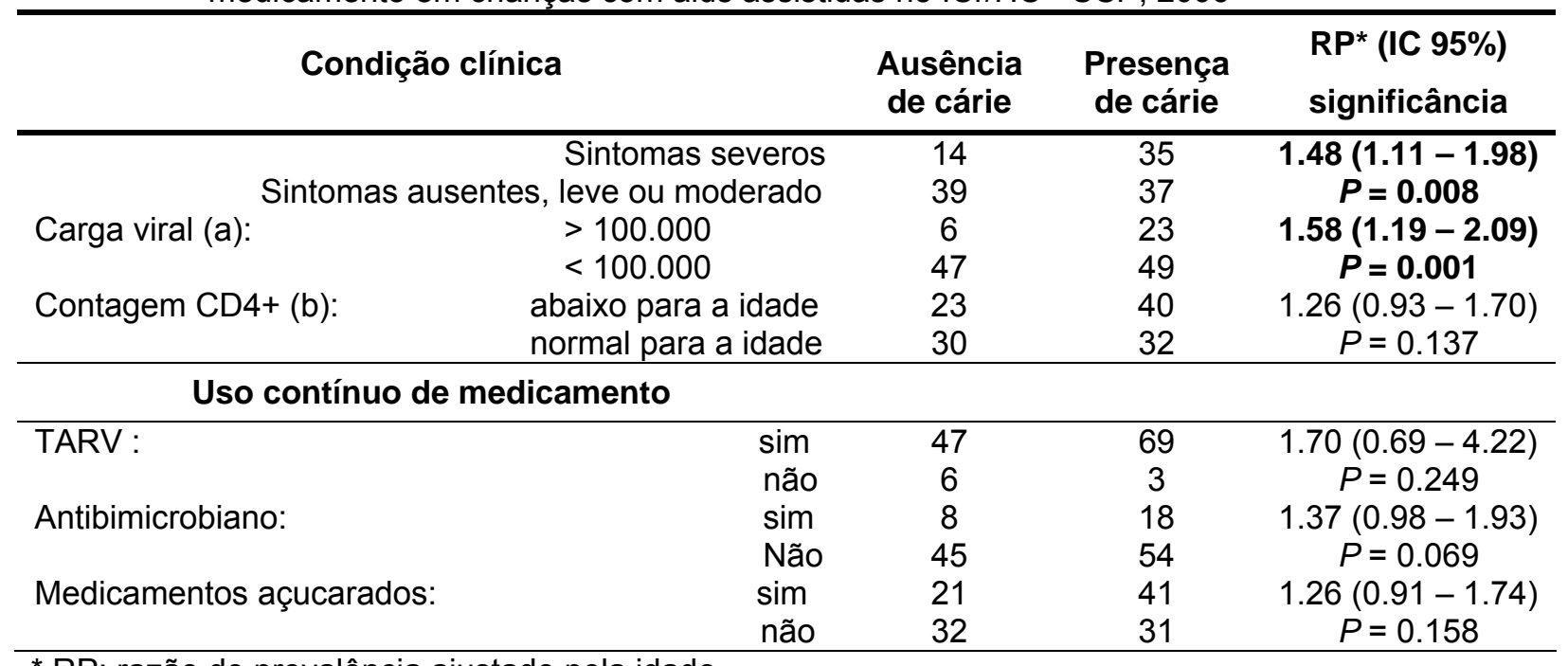

${ }^{*}$ RP: razão de prevalência ajustado pela idade.

(a) Cópias de RNA HIV por milímetro de plasma.

(b) Células linfócitos T CD4 por milímetro cúbico de sangue.

Foi delineado modelo multivariado com ajuste por idade, associando a prevalência de cárie não-tratada com variáveis explicativas de ordem sóciodemográfica (nível de escolaridade do cuidador, aglomeração domiciliar), comportamental (ingestão de açúcar) e clínica (severidade dos sintomas e carga viral). O modelo selecionado explicou a variação de $37 \%$ da medida de desfecho estudada no resultado, e permitiu uma identificação correta de $86 \%$ das crianças com aids que apresentavam necessidade de tratamento de cáries (Tabela 5.10). 
Tabela 5.10 - Associação multivariada entre a prevalência de cárie não-tratada e características das crianças com aids assistidas no ICr/HC - USP, 2006

\begin{tabular}{|c|c|c|}
\hline Característica sócio-demográfica & $\begin{array}{l}\text { RP* (IC 95\%) } \\
\text { Significância }\end{array}$ & valor- $P$ \\
\hline $\begin{array}{l}\text { Escolaridade do cuidador: ensino médio completo } \\
\text { Aglomeração domiciliar: > } 1 \text { hab / cômodo }\end{array}$ & $\begin{array}{l}0,51(0,32-0,83) \\
1,53(1,10-2,13)\end{array}$ & $\begin{array}{l}0,007 \\
0,012\end{array}$ \\
\hline \multicolumn{3}{|l|}{ Característica comportamental } \\
\hline Ingestão diária de açúcar: $\geq 3$ vezes & $1,44(1,10-1,89)$ & 0,008 \\
\hline \multicolumn{3}{|l|}{ Condição clínica } \\
\hline $\begin{array}{l}\text { Gravidade dos sintomas } \\
\text { Carga viral: maior que } 100.000 \text { cópias } / \mathrm{ml}\end{array}$ & $\begin{array}{l}1,39(1.06-182) \\
1,41(1,06-1,87)\end{array}$ & $\begin{array}{l}0,018 \\
0,017\end{array}$ \\
\hline \multicolumn{3}{|l|}{ Qualidade de ajuste } \\
\hline $\begin{array}{lc}\text {-2 loglikelihood } & 207,41 \\
\text { Pseudo-R2 } & 0,37 \\
\text { sensibilidade } & 86 \% \\
\text { especificidade } & 64 \% \\
\end{array}$ & & \\
\hline
\end{tabular}

Todas as associações e o modelo multivariado foram ajustados pela idade, controlando, desse modo, a prevalência mais elevada de cárie não-tratada observada para crianças com dentição decídua. 


\section{DISCUSSÃO}

A freqüência de lesões bucais no grupo aqui estudado foi de 12\% (15/125) e, portanto, abaixo da esperada quando comparada aos $70 \%$ obtidos por Flanagan et al. (2000) e 64\% por Naiddo e Chikte (2004). Segundo Barasch et al. (2000), lesões bucais são mais freqüentes em crianças HIV+/aids (76\%) do que em crianças não-infectadas pelo HIV (36\%). Estes três artigos associam a presença de lesões à baixa contagem de linfócitos CD4, relação esta que não foi encontrada no presente estudo. No trabalho de Ramos-Gomez et al. (2000), a presença de lesão e baixa contagem CD4 também não revelou significância estatística, mas demonstrou que quanto menor o CD4 maior a chance de lesão. Por outro lado, Grando et al. (2002) constataram que as manifestações bucais não ocorreram necessariamente em crianças com baixa contagem CD4, mas associaram com a carga viral acima de 100.000 cóp/ml, que apresentou diferença estatisticamente significante em relação às lesões bucais observadas. Imunossupressão, carga viral elevada e baixa contagem de CD4 foram apontadas por Miziara e Weber (2006), Ramos-Gomez (2002) e Santos et al. (2001) como condições associadas à manifestação de lesões bucais.

Dentre as lesões presentes nas crianças com aids do presente estudo a mais prevalente foi a candidose bucal (8/117; 7\%). Walsh et al. (1998) mencionaram que a candidose bucal ocorre entre $15 \%$ a $40 \%$ das crianças infectadas pelo HIV e Costa et al. (1998) registraram ocorrência em 29\% da população por eles investigada. Para Naidoo e Chikte (2004), a forma clínica mais comum da candidose bucal é a pseudomembranosa, o mesmo registrado neste estudo com crianças do 
$\mathrm{HC}$, pois dos 8 pacientes com candidose bucal, 7 tinham candidose pseudomembranosa.

A prevalência de colonização bucal por Candida foi alta entre as crianças do ICr/HC, atingindo 68\% desses pacientes, porém sendo menor dentre as que faziam uso de TARV do grupo ITRN do que naquelas que recebiam TARV de modo associado (ITRN+ITRNN ou ITRN +IP), ou isolado (ITRNN ou IP). Esses resultados diferem do indicado por Flanagan et al. (2000), pois no estudo destes autores não houve diferença estatisticamente significante na colonização por Candida entre os grupos de crianças submetidos a esquemas terapêuticos diferentes (terapia dupla, ou tripla associada a inibidor de protease).

Embora $C$. albicans seja a espécie mais freqüentemente isolada da mucosa bucal nota-se um aumento na incidência de infecções orais por espécies nãoalbicans (MEILLER et al, 1999; SÁNCHEZ-VARGAS; 2005). Dentre as crianças do ICr/HC, C. albicans foi a espécie mais isolada (80\% dos casos), enquanto as espécies não-albicans representaram $18 \%$ dos casos de colonização da mucosa bucal. A maioria dos trabalhos sobre candidose bucal em crianças com infecção pelo HIV, com idade superior a 1 ano, isolaram maiores porcentagens de cepas da espécie albicans (KETCHEM et al., 1990; MONIACI et al., 1993), diferindo do que foi registrado por LORENA (2000) numa população de 275 crianças HIV+, com menos de 1 ano de idade, na qual a maioria (73\%) estava colonizada por espécies nãoalbicans, e apenas 27\% por albicans. A segunda espécie mais prevalente entre as crianças do ICr/HC foi C. tropicallis, com $6 \%$ dos isolados, dado este muito abaixo do esperado quando comparado aos 55\% registrados por LORENA (2000) para o grupo de crianças infectadas pelo HIV. 
Candida dubliniensis é fenotipicamente semelhante a C. albicans, fato que tem gerado discussões quanto a identificação dos isolados clínicos (GIAMMANCO et al., 2002). Segundo Mariano et al. (2003), na América do Sul a prevalência de isolados de $C$. dubliniensis parece ser menor do que aquela encontrada por países da América do Norte. A incidência de C. dubliniensis em pacientes HIV+ e com aids, observada no Brasil, mostrou ser menor do que na Europa e EUA.

Milan et al (2001) realizaram o primeiro estudo prospectivo multicêntrico com relação a incidência bucal de $C$. dubliniensis em pacientes brasileiros HIV+/aids. No período de dois anos, foram pesquisados seis centros médicos terciários com atividades no tratamento de pacientes HIV em todo Brasil. De um total de 155 amostras isoladas, 13 foram re-identificadas fenotipicamente como $C$. dubliniensis. Destas apenas 4 foram confirmadas pelas técnicas moleculares, PCR e RAPD, representando uma taxa de incidência de 2,8\%. Em outros paises sua incidência é um pouco mais elevada, variando de 11\% a 32\% (COLEMAN et al., 1997; KIRKPATRICK et al., 1998; MEILLER, 1999; SULLIVAN et al., 1999).

Vários métodos para a discriminação e identificação de $C$. dubliniensis tem sido relatados, incluindo aqueles utilizados neste estudo, sendo estes a cultura em meio CHROMagar Candida e avaliação da habilidade de crescimento a temperatura de $42^{\circ} \mathrm{C}$ (SULLIVAN; COLEMAN, 1997; SULLIVAN et al., 1995). Dentre as crianças do ICr/HC não foi identificado nenhum caso de colonização por $C$. dubliniensis, usando-se testes fenotípicos clássicos, cultura em meio cromogênico e habilidade de crescimento a $42^{\circ} \mathrm{C}$, métodos esses que geraram resultados satisfatórios em outros estudos (SULLIVAN; COLEMAN, 1997; TINTELNOT et al., 2000).

Em relação à necessidade de tratamento dentário e presença de Candida, houve uma associação fortemente positiva ( $86 \%$ dos casos), resultado este que 
corrobora o registro feito por JACOB et al. (1998), os quais demonstraram haver relação entre colonização por Candida e lesão cariosa na dentina de pacientes HIV+/aids. Embora JACOB et al. (1998) tenham avaliado uma população adulta, 75\% desses pacientes HIV+ tinham a dentina cariada colonizada por Candida, e 40\% apresentavam manifestação clínica de candidose bucal, enquanto $17 \%$ de pacientes HIV- também apresentavam colonização por Candida, mas sem manifestação clínica de candidose.

Entre as crianças do $\mathrm{ICr} / \mathrm{HC}$ constatou-se associação entre cultura positiva para Candida e características sócio-demográficas das crianças, identificando maior prevalência de colonização por Candida em crianças que não moravam em casas próprias e tinham mais de dois irmãos. Essas associações sugerem que pacientes com pior condição socioeconômica são mais vulneráveis à infecção por Candida, mas este dado não pôde ser confirmado por não haver trabalhos semelhantes referenciados na literatura.

Dados da pesquisa do Projeto SB Brasil (2003), no Estado de São Paulo, revelaram prevalência de $44,7 \%$ de cáries não-tratadas para população de 5 anos de idade e de $34,8 \%$ para crianças de 12 anos. Adotando-se esses valores como parâmetro para comparação dos resultados do presente estudo com crianças do ICr/HC de 3 a 15 anos, nas quais a prevalência de cáries não-tratadas foi de 58\%, constata-se que crianças com aids apresentam pior condição dentária do que a população de crianças do estudo acima referido. Tofsky et al. (2000), ao compararem 104 crianças HIV+ com irmãos não infectados por esses vírus, identificaram que a prevalência de cárie dentária foi maior no primeiro grupo, semelhante ao que Madigan et al. (1996) haviam constatado em um estudo do tipo 
caso controle com 147 crianças, no qual o ceo médio das infectadas $(3,8)$ era mais que o dobro da média de seus irmãos soronegativos $(1,5)$.

Fatores sócio-demográficos como renda familiar abaixo de 2 salários mínimos, baixo grau de escolaridade dos cuidadores, aglomeração domiciliar e número de dependentes contribuíram para a prevalência de cárie na mostra de crianças com aids do ICr/HC. Pacientes com pior condição socioeconômica têm menos acesso aos serviços privados de odontologia, e sofrem restrições do atendimento na rede pública que não suporta toda a demanda existente. O estudo de Antunes et al. (2002), mostra que crianças de baixa renda na população em geral da cidade de São Paulo utilizam de forma reduzida os serviços de saúde bucal.

No contexto brasileiro, a aglomeração domiciliar tem sido usada como um indicador de condição socioeconômica, quando da realização de estudos epidemiológicos que avaliam a distribuição de cárie dentária numa população, pois indivíduos mais expostos a privações tendem a residir em domicílios com maior densidade populacional (ANTUNES et al., 2002). Ter mais de dois irmãos também foi indicado em nosso estudo como fator associado com a prevalência de cárie dentária em pacientes com aids, pois os pais ou cuidadores têm que dividir sua atenção e cuidados quase simultaneamente entre todas as crianças, o que lhes impõe maior dificuldade para controlar a alimentação, higiene bucal e tratamento odontológico das mesmas. Residir em domicílios aglomerados e ter mais de dois irmãos são condições em geral simultâneas e apresentaram colinearidade na análise estatística. Nesse sentido, para a análise de regressão realizada neste estudo, a primeira dessas variáveis foi selecionada para o ajuste do modelo multivariado. 
A avaliação da freqüência de ingestão de alimentos e bebidas açucaradas associou significantemente com a prevalência de cárie não-tratada; portanto, foi selecionada também para o modelo multivariado como uma das variáveis explicativas mais relevantes. A freqüência de ingestão de alimentos ricos em carboidratos é bem conhecida como fator de risco para o surgimento de cárie. A associação entre quantidade de carboidratos ingeridos e prevalência de cáries foi relatada por Camargo e Antunes (2007) em pacientes pediátricos com outras condições sistêmicas. Embora Bigeard (2000) tenha relatado que o uso freqüente de medicamentos contendo açúcar seja uma das causas de cárie dentária em crianças com doenças crônicas, o uso contínuo de medicamentos açucarados pelas crianças do ICr/HC não apresentou significância estatística em relação à prevalência de cárie não-tratada.

Condições clínicas das crianças do ICr/HC associaram significantemente com a prevalência de cárie não-tratada. Cárie dentária e restrição ao tratamento odontológico podem afetar crianças com carga viral elevada ou com manifestação de sintomas severos da aids. O estudo de Castro et al. (2001), aplicado ao contexto brasileiro associou a prevalência de cárie com a condição clínica e imunológica de crianças infectadas pelo HIV. Isso pode ser devido ao fato de que crianças HIV+/aids em estágios mais avançados da doença fazem uso mais freqüente de medicamentos e estes, não raro, contêm elevado teor de açúcar. Nesses estágios mais avançados, a realização da higiene oral pode ser bastante prejudicada pela presença de lesões bucais (FLAITZ et al., 2001).

A prevalência de cárie não-tratada entre as crianças com aids do $\mathrm{ICr} / \mathrm{HC}$ foi maior para as que apresentavam carga viral mais elevada e menor contagem de CD4. Esses fatores podem indicar redução dos mecanismos tanto da imunidade 
geral como da imunidade local, provavelmente associada a IgA secretória salivar, o que facilitaria o desenvolvimento de processos cariogênicos. Resultados de estudos como o de Hicks et al. (2000), também apresentaram alta prevalência de cárie associada à baixa contagem CD4.

Sendo uma condição crônica, a cárie dentária tem sua distribuição associada à exposição cumulativa aos fatores de risco ao longo do tempo. Nesse sentido, os índices convencionalmente utilizados para aferir a prevalência de cárie, CPO-D para dentes permanentes e ceo-d para dentes decíduos (WORLD HEALTH ORGNIZATION, 1997), são dependentes da idade, e se aplicam a grupos etários específicos. O acesso a tratamento odontológico, que é usualmente aferido pelo “índice de cuidado odontológico" proposto por Walsh (1970), avalia a proporção de dentes restaurados em relação ao total de dentes com histórico de cárie. Como esse índice varia com a idade, também precisa ser avaliado em relação a grupos etários bem delimitados. Os requisitos impostos para determinação desses índices não possibilitaram sua avaliação para as crianças HIV+/aids do ICr/HC, devido a ampla variação etária da amostra, bem como do número reduzido de crianças em cada grupo.

Nesse sentido, a avaliação de prevalência de cárie não-tratada nesse grupo de crianças, com controle estatístico da idade na análise de regressão, foi a estratégia que permitiu incluir o total da amostra na análise comparativa, apesar de sua amplitude de variação etária. A medida de prevalência de cárie não-tratada reflete a complexa interação entre a exposição progressiva ao risco de cárie e ao acesso a tratamento odontológico. Assim, é possível dizer que essa variável sintetiza indicadores simultâneos em ambas as dimensões (ANTUNES et al., 2006). 
A avaliação de risco de cárie em crianças com aids poderia ser beneficiada por esquemas metodológicos alternativos, por exemplo, reunindo informação longitudinal sobre a incidência de cáries, ou comparando grupos de crianças com e sem aids (COSTA et al., 1998; MADIGAN, 1996; TOFSKY et al., 2000). Uma avaliação mais extensa do risco de cárie, entretanto, não pôde ser realizada, o que também é indicado como limitação do presente estudo.

O presente estudo mostrou que as crianças HIV+/aids também têm maior prevalência de problemas odontológicos que a população de crianças em geral. Apesar disso, a prevalência de lesão bucal e de infecção por Candida não foi elevada, indicando que o protocolo terapêutico da aids tem contribuído para reduzir determinados tipos de infecção na mucosa bucal dessas crianças, e nessas condições clínicas. 


\section{CONCLUSÕES}

1. A manifestação clínica da candidose bucal foi baixa entre os pacientes avaliados, considerando que a maioria das crianças apresentava baixa contagem CD4 e alta carga viral e colonização por Candida;

2. Candida albicans foi a espécie mais prevalente, seguida em ordem decrescente por C. tropicallis, C. kefyr, C. krusei, C. glabrata e C. guilliermondii;

3. Estudos moleculares são necessários para se confirmar a suspeita de ocorrência C dubliniensis, deixada com o emprego apenas de testes fenotípicos;

4. Crianças com aids têm pior condição dentária em ambas as dentições, do que crianças na população em geral, sem aids, com idade correspondente. 


\section{REFERÊNCIAS ${ }^{1}$}

Aguirre JM, Echebarria MA, Ocina E, Ribacoba L, Montejo M. Reduction of HIVassociated oral lesions after higly active antiretroviral therapy. Oral Surg Oral Med Oral Pathol Oral Radiol End 1999;88(2):114-5.

Aids: etiologia, clínica, diagnóstico e tratamento. Unidade de Assistência. Disponível em: www.aids.gov.br/assitencia/etiologia diagnostico.htm [fevereiro de 2006].

AIDS. Boletim Epidemiológico 1998;11(4).

Aids Institute. Criteria for the medical care of children and adolescents with HIV infection. New Cork: Department of Health; 1998,259p.

Al Moisaid A, Sullivan D, Salkin IF, Shanley D, Coleman DC. Differentiation of Candida dubliniensis from Candida albicans on staib agar and caffeic-ferric citrate agar. J Clin Microbiol 2001;39(1):323-7.

Alves SH, Milan EP, de Laet Sant'Ana P, Oliveira LO, Santurio JM, Colombo AL. Hypertonic sabouraud broth as a simple and powerful test for Candida dubliniensis screening. Diagn Microbiol Infect Dis 2002;43(1):85-6.

Ammann A, Cowan M, Wara D, Goldman H, Perkins H, Lanzerotti R, et al. Posible transfusión-associated Acquired Immune Deficiency Síndrome (AIDS) - California. MMWR Morb Mortal Wkly Rep 1982;31(48):652-4.

Andrade AT. AIDS e reprodução - alguns aspectos. Bol Cent Biol Reprod 1990; 9(1):7-9.

Antunes JLF, Frazão P, Narvai PC, Bispo CM, Pegoretti T. Spatial analysis to identify differentials in dental needs by area-based measures. Community Dent Oral Epidemiol 2002; 30:133-42.

\footnotetext{
${ }^{1}$ De acordo com Estilo Vancouver. Abreviatura de periódicos segundo base de dados MEDLINE.
} 
Antunes JLF, Peres MA, Mello TRC, Waldman EA. Multilevel assessment of determinants of dental caries experience in Brazil. Community Dent Oral Epidemiol 2006; 34:146-52.

Arikan S, Darka O, Hascelik G, Gunalp A. Identification of Candida dubliniensis strains using heat tolerance tests, morphological characteristics and molecular methods. Mikrobiyol Bul 2003;37(1):49-57.

Atkinson JC, Yeh C, Oppenheim FG, Baum BJ, Fox PC. Elevation of salivary antimicrobial proteins following HIV - 1 infection. J Acquir Immune Def Syndr 1990;3 (1):41-8.

Axell T, Samaranayake LP, Reichart PA, Olsen L. A proposal for reclassification of bucal candidiasis. Bucal Surg Bucal Med Bucal Pathol Radiol Endod 1997;84:111-2.

Barasch A, Safford MM, Catalanotto FA, Fine DH, Katz RV. Oral soft tissue manifestations in HIV-positive vs. HIV negative children from an inner city population: a two-year observational study. Pediatr Dent 2000;22(3):215-20.

Barros AJD, Hirakata VN. Alternatives for logistic regression in cross-sectional studies: an empirical comparison of models that directly estimate the prevalence ratio. BMC Med Res Methodol 2003;3:21.

Bazin AR. Infecções causadas pelo vírus da imunodeficiência humana. Síndrome da imunodeficiência adquirida. In: Passos MRL. Doenças sexualmente transmissíveis. 4. ed. Rio de Janeiro: Cultura Médica; 1995. cap. 23, p. 276-306.

Bigeard L. The role of medication and sugars in pediatric dental patients. Dent Clin North Am 2000;44:443-56.

Blignaut E. Oral candidiasis and oral yeast carriage among institutionalised South African paediatric HIVIAIDS patients. Mycopathologia 2007;163(2):67-73.

Bodey GP. Candidiasis: Pathogenesis, diagnosis and treatment. $2^{\text {nd }}$ ed. New York: Raven Press; 1993.

Bosco VL. Manifestações bucais, microbiota bacteriana e fúngica em crianças com AIDS e seus controles [Tese de Doutorado]. São Paulo: Faculdade de Odontologia da USP; 1998. 
Bosco VL, Birman EG. Oral manifestations in children with AIDS and in controls. Pesqui Odontol Bras 2002;16(1):7-11.

Bosco VL, Birman EG, Cury AE, Paula CR. Yeast from the oral cavity of children with AIDS: exoenzyme production and antifungal resistance. Pesqui Odontol Bras 2003;17(3):217-22.

Brandt ME, Harrison LH, Pass M, Sofair AN, Huie S, Morrison CJ et al. Candida dubliniensis fungemia: the first four cases in North America. Emerg Infect Diseases 2000;6(1):46-9.

Brasil. Ministério da Saúde. Secretaria de Assistência à Saúde. Coordenação-Geral do PN DST/AIDS. Unidade de Promoção à Saúde e Assistência. Aleitamento X mulheres infectadas pelo HIV: recomendações. Brasília; 1995. 14 p.

Brasil. Ministério da Saúde. Controle de infecção e a prática odontológica em tempos de AIDS: manual de condutas. Brasília; 2000a. 118p.

Brasil. Ministério da Saúde. Coordenação Nacional de DST e AIDS. Guia de tratamento clínico da infecção pelo HIV em crianças. Brasília; 2001. 30p.

Brasil. Ministério da Saúde. Coordenação Nacional de DST e AIDS. Boletim epidemiológico AIDS. Brasília; 2004a.

Brasil. Ministério da Saúde. Definição nacional de caso de AIDS em indivíduos menores de 13 anos, para fins de vigilância epidemiológica. Brasília; 2000b.

Brasil. Ministério da Saúde. Secretaria Programa Nacional de DST e AIDS. Guia de tratamento clínico da infecção pelo HIV em crianças. Brasília; $2004 b$.

Brasil. Ministério da Saúde. Secretaria de Vigilância em Saúde. Programa Nacional de DST e AIDS. Dados epidemiológicos - AIDS. Boletim epidemiológico - AIDS e DST 2006;3(1):30-40.

Bravo IM, Correnti M, Escalona L, Perrone M, Brito A, Tovar V, et al. Prevalence of oral lesions in HIV patients related to CD4 cell count and viral load in a Venezuelan population. Med Oral Patol Oral Cir Bucal 2006;11(1):E33-9. 
Brawner DL, Hovan AJ. Oral candidiasis in HIV-infected patients. Curr Top Med Mycol 1995;6:113-25.

Bretz WA, Flaitz C, Moretti A, Corby P, Schneider LG, Nichols CM. Medication usage and dental caries outcome-related variables in HIVIAIDS patients. AIDS Patient Care STDS 2000;14:549-54.

Brown DM, Jabra-Rizk MA, Falkler WA Jr, Baqui AA, Meiller TF. Identification of Candida dubliniensis in a study of HIV- seropositive pediatric dental patients. Pediatr Dent 2000;22(3):234-8.

Brunelle JA. Caries attack in the primary dentition of U.S. children [abstract 575]. J Dent Res 1990;69:180.

Calvelli TA, Rubinstein A. Pediatric HIV infection: a review. Immunodefic Rev 1990;2(2):83-127.

Camargo MAF, Antunes JLF. Untreated dental caries in children with cerebral palsy in the Brazilian context. Int J Paediatr Dent 2007;17: forthcoming article

Cassone A, De Bernardis F, Torosantucci A, Tacconelli E, Tumbarello M, Cauda R. In vitro and in vivo anticandidal activity of human immunodeficiency virus protease inhibitors. J Infect Dis 1999;180(2):448-53.

Castro GF. Correlação entre manifestações bucais e classificação clínica e imunológica em crianças infectadas pelo HIV [Dissertação de Mestrado]. Rio de Janeiro: Faculdade de Odontologia da UFRJ; 1998.

Castro GF, Souza IPR, Oliveira RHS, Portela MB, Esteves C. Prevalência de cárie e sua correlação com a classificação clínica e imunológica em crianças infectadas pelo HIV. Pesqui Odontol Bras 2001;15:91-7.

Ceccotti LE. Ninos com SIDA: manifestaciones bucales. Rev Asoc Odontol Argent 1995;83(4):299-303.

Centers for Disease Control and Prevention. Classification system for human immunodeficiency virus (HIV) infection in children Ander 13 years of age. MMWR 1987;36:225-30. 
Centers for Disease Control and Prevention. Revised classification system for HIV infection in children less than 13 years of age. MMWR 1994;43(RR-12):1-10.

Chan A, Milnes A, King SM. The relationship of oral manifestations to parameters of immune function and CDC state in children born to HIV positive women. Pediatr AIDS HIV Infection 1994;15:101-7.

Chigurupati R, Raghavans S, Studen-Pavlovich DA. Pediatric HIV infection and its oral manifestations: a review. Pediatr Dent 1996;18(2):106-13.

Cimolai N, Davis J, Trombley C. Candida dubliniensis fungemia and vascular access infection. J. Pediatr. Hematol. Oncol 2002;24(3):237-9.

Coleman D, Sullivan D, Harrington B, Haynes K, Henman M, Shanley D, et al. Molecular and phenotypic analysis of Candida dubliniensis: a recently identified species linked with oral candidosis in HIV-infected and AIDS patients. Oral Dis 1997;3(Suppl 1):S96-101.

Costa LR, Villena RS, Sucasas PS, Birman EG. Oral findings in pediatric AIDS: a case control study in Brazilian children. ASDC J Dent Child 1998;65(3):186-90.

Costa CR, Cohen AJ, Fernandes OFL, Miranda KC, Passos XS, Souza LKH et al. Asymptomatic oral carriage of Candida species in HIV-infected patients in the highly active antiretroviral therapy era. Rev Inst Med Trop S Paulo 2006;48(5):257-61.

Costa CR, de Lemos JA, Passos XS, de Araujo CR, Cohen AJ, Souza LK, Silva Mdo $R$. Species distribution and antifungal susceptibility profile of oral candida isolates from HIV-infected patients in the antiretroviral therapy era. Mycopathologia 2006;162(1):45-50.

Cotran RS, Kumar V, Robbins SL. Robbins: patología estrutural e funcional. 5. ed. Rio de Janeiro: Guanabara Koogan; 1996. p. 194-204.

Culnane M, Fowler M, Lee SS, McSherry G, Brady M, O'Donnell K, et al. Lack of long-term effects of in utero exposure to zidovudine among uninfected children born to HIV-infected women. Pediatric AIDS Clinical Trials Group Protocol 219/076 Teams. J Am Med Assoc 1999;281(2):151-7.

Darwazeh AM, al-Bashir A. Oral candidal flora in healthy infants. J Oral Pathol Med 1995;24(8):361-4. 
Datry A. Candidose digestive et infection VHI. Actualités cliniques et therapeutiques. J Mycol Med 1992;2(Suppl 1):5-14.

Dattani I, Ganatra S. Oral manifestations of HIV infections. Oral Health 1993;83(7):15-7.

Deeks SG, Smith M, Holodniy M, Kahn JO. HIV-1 protease inhibitors. A review for clinicians. J Am Med Assoc 1997;277(2):145-53.

Delgado W, Aguirre JM. Oral mycoses in the AIDS era. Rev Iberoam Micol 1997;14(1):14-22.

Diz Dios P, Ocampo A, Otero I, Iglesias I, Martinez C. Changes in oropharyngeal colonization and infection by Candida albicans in human immunodeficiency virusinfected patients. J Infect Dis 2001;183(2): 355-6.

Dupont B, Denning DW, Marriott D, Sugar A, Viviani MA, Sirisanthana T. Mycosis in AIDS patients. J Med Vet Mycol 1994;32(Suppl 1):65-77.

Fabro SML, Ody E, Grando LJ, Peres KG, Rath IBS. Alterações estomatológicas e condições dentais em crianças infectadas pelo HIV. Arq Odontol 2002;38(3):201-11.

Fernandez Feijoo J, Diz Dios P. Oral candidiasis in human immunodeficiency virusinfected women. Oral Surg Oral Med Oral Pathol Oral Radiol Endod 2002;93(3):219.

Ferguson FS, Nachman S, Berentsen B. Implications and management of oral diseases in children and adolescents with HIV infection. Pediatr Dent $1997 ; 63(2): 46-50$.

Fidel PL Jr, Vazquez JA, Sobel JD. Candida glabrata: review of epidemiology, pathogenesis, and clinical diseases with comparison to C. albicans. Clin Microbiol Rev 1999;12(1):80-96.

Flaitz C, Wullbrandt B, Sexton J, Bourdon T, Hicks J. Prevalence of orodental findings in HIV-infected Romanian children. Pediatr Dent 2001;23(1):44-50.

Flanagan MA, Barasch A, Koenigsberg SR, Fine D, Houpt M. Prevalence of oral soft tissue lesions in HIV-infected minority children treated with highly active antiretroviral therapies. Pediatr Dent 2000;22(4):287-91. 
Fonseca R, Cardoso AS, Pomarico I. Frequency of oral manifestations in children infected with human immunodeficiency virus. Quintessence Int 2000;31(6):419-22.

Ghersel ELA, Rodrigues CLMD, Tannous GS. AIDS em odontopediatria: uma realidade atual. Rev Bras Odontol 1999;56(6):282-87.

Giammanco GM, Pizzo G, Pecorella S, Distefano S, Pecoraro V, Milici ME. Identification of Candida dubliniensis among oral yeast isolates from an Italian population of human immunodeficiency virus-infected $(\mathrm{HIV}+)$ subjects. Oral Microbiol Immunol 2002;17(2):89-94.

Giusiano GE, Mangiaterra ML. Diferenciación e identicatión presuntiva rapida de leveduras com el media CHROM-agar Candida. Rev Argent Microbiol 1998;30:100-3.

Gottlieb MS, Schroff R, Schanker HM, Weisman JD, Fan PT, Wolf RA, et al. Pneumocystis carinii pneumonia and mucosal candidiasis in previously healthy homosexual men: evidence of a new acquired cellular immunodeficiency. $\mathrm{N}$ Engl J Med 1981;305(24):1425-31.

Gortmaker SL, Hughes M, Cervia J, Brady M, Johnson GM, Seage GR3rd, et al. Effect of combination therapy including protease inhibitors on mortality among children and adolescents infected with HIV-1. N Engl J Med Nov 2001;345(21):1522-8.

Grando LJ, Yurgel LS, Machado DC, Silva CL, Menezes M, Picolli C. Oral manifestations, CD4+ T-lymphocytes count and viral load in Brazilian and NorthAmerican HIV-infected children. Pesqui Odontol Bras 2002;16(1):18-25.

Grando LJ, Yurgel LS, Machado DC, Nachman S, Ferguson F, Berentsen B, et al. The association between oral manifestations and the socioeconomic and cultural characteristics of HIV-infected children in Brazil and in the United States. Pan Am J Publ Health 2003;14:112-8.

Groopman JE, A síndrome de imunodeficiência adquirida. In: Wyngaarden JB, Smyth JR LH. Tratado de medicina interna. 18. ed. Rio de Janeiro: Guanabara; 1990. v. 2, cap. 346, p.1573-80.

Gruber A, Berlit J, Speth C, Lass-Flori C, Kofler G, Nagl M, et al. Dissimilar attenuation of Candida albicans virulence properties by human immunodeficiency virus type 1 protease inhibitors. Immunobiology 1999;201(1):133-44. 
Guidelines for the use of antiretroviral agents in pediatric HIV infection. New Cork: Working Group on Antiretroviral Therapy and Medical Management of HIV-infected Children; 2000. 58p.

Gutierrez J, Morales P, Gonzalez MA, Quindos G. Candida dubliniensis, a new fungal pathogen. J Basic Microbiol 2002;42(3):207-27.

Hammer SM, Squires KE, Hughes MD, Grimes JM, Demeter LM, Currier JS, et al. A controlled trial of two nucleoside analogues plus indinavir in persons with human immunodeficiency virus infection and CD4 cell counts of 200 per cubic millimeter or less. N Engl J Med 1997;337(11):725-33.

Hannula J, Saarela M, Dogan B, Paatsama J, Koukila-Kahkola P, Pirinen S, et al. Comparison of virulence factors of oral Candida dubliniensis and Candida albicans isolates in healthy people and patients with chronic candidosis. Oral Microbiol Immunol 2000;15(4):238-44.

Hernandez M, Boj J. Oral manifestation of the paediatric infection with HIV vírus. In: Annals of international workshop on the oral manifestation of hiv infection, 1996. London; 1996.

Hicks MJ, Flaitz CM, Carter AB, Cron SG, Rossmann SN, Simon CL, Demmler GJ, Kline MW. Dental caries in HIV-infected children: a longitudinal study. Pediatr Dent 2000;22(5):359-64.

Hoegl L, Ollert M, Korting HC. The role of Candida albicans secreted aspartic proteinase in the development of candidoses. J Mol Med 1996;74(3):135-42.

Holmstrup P, Samaranayake LP. Acute and AIDS-related bucal candidotes. In: Samaranayake LP, MacFarlane TW, editors. Oral candidosis. London: Wright; 1990. p. 133-55.

Howell RB, Jandinski J, Palumbo P, Shey Z, Houpt M. Dental caries in HIV-infected children. Pediatr Dent 1992;14(6):370-1.

Howell RB, Jandinski JJ, Palumbo P, Shey Z, Houpt MI. Oral soft tissue manifestations and CD4 lymphocyte counts in HIV-infected children. Pediatr Dent 1996;18(2):117-20. 
Jabra-Rizk MA, Falkler WA, Enwonwu CO, Onwujekwe DI, Merz WG, Meiller TF. Prevalence of yeast among children in Nigeria and the United States. Oral Microbiol. Immunol 2001;16(6):383-5.

Jacob LS, Flaitz CM, Nichols CM, Hicks MJ. Role of dentinal carious lesions in the pathogenesis of oral candidiasis in HIV infection. J Am Dent Assoc 1998;129(2):18794.

Kadir T, Uygun B, Akyuz S. Prevalence of Candida species in Turkish children: relationship between dietary intake and carriage. Arch Oral Biol 2005;50(1):33-7.

Katz MH, Mastrucci MT, Leggott P, Westenhouse J, Greenspan JS, Scott GB. Prognostic significance of oral lesions in children with perinatally acquired human immunodeficiency vírus infection. Am J Dis Child 1993;147:45-8.

Ketchem L, Berkowitz RJ, Mcllveen L, Forrester D, Rakusan T. Oral findings in HIVseropositive children. Pediatr Dent 1990;12(3):143-6.

Kirkpatrick WR, Revankar SG, Mcatee RK, Lopez-Ribot JL, Fothergill AW, McCarthy DI, et al. Detection of Candida dubliniensis in oropharyngeal samples from human immunodeficiency virus-infected patients in North America by primary CHROMagar candida screening and susceptibility testing of isolates. J Clin Microbiol 1998;36(10):3007-12.

Klein RS, Harris CA, Small CB, Moll B, Lesser M, Friedland GH. Oral candidiasis in high-risk patients as the initial manifestation of the acquired immunodeficiency syndrome. N Engl J Med 1984;311:354-8.

Korting HC, Schaller M, Eder G, Hamm G, Böhmer U, Hube B. Effects of the human immunodeficiency virus (HIV) proteinase inhibitors saquinavir and indinavir on in vitro activities of secreted aspartyl proteinases of Candida albicans isolates from HIVinfected patients. Antimicrob Agents Chemother 1999;43(8):2038-42.

Kurtzman CP, Fell JW. The yeasts: a taxonomic study. $4^{\text {th }}$ ed. Amsterdan: Elsevier; 1998.

Legott PJ. Oral manifestations of HIV infection in children. Oral Surg Oral Med Oral Pathol 1992;73(2):187-92. 
Lewis MA, Samaranyake LP, Lamey PJ. Diagnosis and treatment of oral candidosis. J Oral Maxillofac Surg 1991;49(9):996-1002.

Lima OCC, Silveira FRX, Birman EG. Manifestações bucais de origem infecciosa em pacientes HIV-positivos ou com AIDS - I. Doenças fúngicas. Rev Assoc Bras Odontol 1994;2(1):28-32.

Little JM, Melnick SL, Rhame FS, Balfour HH, Decher L, Rhodus NL, Merry JW, Walker PO, Miller CE, Volberding P. Prevalence of oral lesions in symptomatic and asymptomatic HIV patients. Gen Dent 1994;42(5):446-50.

Lloyd A. HIV infection and AIDS. P N G Med J 1996;39(3):174-80.

Lorena H. Colonização fúngica da cavidade oral de crianças nascidas de mães soropositivas para HIV no primeiro ano de vida [Dissertação de Mestrado]. São Paulo: - Escola Paulista de Medicina da UNIFESP; 2000.

Louie JK, Hsu LC, Osmond DH, Katz MH, Schwarcz SK. Trends in causes of death among persons with acquired immunodeficiency syndrome in the era of highly active antiretroviral therapy, San Francisco, 1994-1998. J Infect Dis 2002;186:1023-7.

Lynch DP. Oral candidiasis. History, classification, and clinical presentation. Oral Med Oral Pathol 1994;78:189-93.

Mackie IC, Bentley E. Sugar-containing or sugar-free paediatric medicines: does it really matter? Dent Update 1994;21:192-4.

Madigan A, Murray PA, Houpt M, Catalanotto F, Feuerman M. Caries experience and cariogenic markers in HIV-positive children and their siblings. Pediatr Dent 1996;18:129-36.

Magalhães MG, Bueno DF, Serra E, Gonçalves R. Oral manifestations of HIV positive children. J Clin Pediatr Dent 2001;25(2):103-6.

Margiota V, Campisi G, Mancuso S, Accurso V, Abbadessa V. HIV infection: oral lesions, CD4+ cell count and viral load in an Italian study population. J Oral Pathol Med 1999;28(4):173-7. 
Mariano PLS, Milan EP, Matta DA, Colombo AL. Candida dubliniensis identification in Brazilian yeast stock collection. Mem Inst Oswaldo Cruz 2003;98:533-8.

Mattos-Graner RO, de Moraes AB, Rontani RM, Birman EG. Relation of oral yeast infection in Brazilian infants and use of a pacifier. ASDC J Dent Child 2001;68(1):33-6.

McCarthy GM. Host factors associated with HIV-related oral candidiasis. Oral Surg Oral Med Oral Pathol 1992;73:181-6.

Meiller TF, Jabra-Rizk MA, Baqui A, Kelley JI, Meeks VI, Merz WG, Falkler WA. Oral Candida dubliniensis as a clinically important species in HIV-seropositive patients in the United States. Oral Surg Oral Med Oral Pathol Oral Radiol Endod 1999;88(5):573-80.

Meis JF, Ruhnke M, De Pauw BE, Odds FC, Siegert W, Verweij PE. Candida dubliniensis candidemia in patients with chemotherapy-induced neutropenia and bone marrow transplantation. Emerging Infect Dis 1999;5(1):150-3.

Michelet C, Arvieux C, François C, Besnier JM, Rogez JP, Breux JP, et al. Opportunistic infections occurring during highly active antiretroviral treatment. AIDS 1998;12:1815-22.

Migliorati CA, Birman EG, Cury AE. Oropharyngeal candidiasis in HIV-infected patients under treatment with protease inhibitors Oral Surg Oral Med Oral Pathol Oral Radiol Endod 2004;98(3):301-10.

Milan EP. Estudo microbiológico de leveduras isoladas da cavidade oral de pacientes com AIDS [Dissertação de Mestrado]. São Paulo: - Escola Paulista de Medicina da UNIFESP; 1997.

Milan EP, de Laet Sant' Ana P, de Azevedo Melo AS, Sullivan DJ, Coleman DC, Lewi $D$, et al. Multicenter prospective surveillance of oral Candida dubliniensis among adult Brazilian human immunodeficiency virus-positive and AIDS patients. Diagn Microbiol Infect Dis 2001;41(1-2):29-35.

Miller CR. Pediatric aspects of AIDS. Adiol Clin North Am 1997;35(5):1191-221.

Miziara ID, Weber R. Oral candidosis and oral hairy leukoplakia as predictors of HAART failure in Brazilian HIV-infected patients. Oral Dis 2006;12(4):402-7. 
Miziara ID, Araujo Filho BC, Weber R. Oral lesions in Brazilian HIV-infected children undergoing HAART. Int J Pediatr Otorhinolaryngol 2006;70(6):1089-96.

Moniaci D, Greco D, Flecchia G, Raiteri R, Sinicco A. Epidemiology, clinical features and prognostic value of HIV-1 related oral lesion. J Oral Pathol Med 1990;19(10):477-81.

Moniaci D, Cavallari M, Greco D, Bruatto M, Raiteri R, Palomba E, et al. Oral lesion in children born to HIV-1 positive women. J Oral Pathol Med 1993;22:8-11.

Mouton Y, Alfandari S, Valette M, Cartier F, Dellamonica P, Humbert G, et al. Impact of protease inhibitors on AIDS-defining events and hospitalizations in 10 French AIDS reference centres. AIDS 1997 Oct;11(12):F101-5.

Naidoo S, Chikte U. Oro-facial manifestations in paediatric HIV: a comparative study of institutionalized and hospital outpatients. Oral Dis 2004;10:13-8.

Nicolatou O, Theodoridou M, Mostrou G, Velegraki A, Legakis NJ. Oral lesions in children with perinatally acquired human immunodeficiency virus infection. J Oral Pathol Med 1999;28(2):49-53.

O’Relly R, Kirkpatrick D, Small CB et al. Unexplained immunodeficiency and opportunistic infection in infants - New Cork, New Jersey, California. MMWR Morb Mortal Wkly Rep 1982;31(49):665-7.

Odds FC, Bernaerts R. CHROMagar Candida, a new differential isolation medium for presumptive identification of clinically important Candida species. J. Clin. Microbiol 1994;32(8):1923-9.

Odds FC, Van Nuffel L, Dams G. Prevalence of Candida dubliniensis isolates in a yeast stock collection. J Clin Microbiol 1998;36(10):2869-73.

Oliveira MS et al. Virologia. In: Lima AL et al. HIVIAIDS: perguntas e despostas. São Paulo: Atheneu;1996. cap.2, p. 31-43.

Organização Mundia da Sáude/Fundo das Nações Unidas para a infância. Ações em prol de crianças afetadas pela AIDS: perfis programáticos e lições aprendidas.

Brasília, 1996. 195p. 
Palella FJ Jr, Delaney KM, Moorman AC, Loveless MO, Fuhrer J, Satten GA et al. Declining morbidity and mortality among patients with advanced human immunodeficiency virus infection. HIV outpatients study investigators. N Engl J Med 1998;338(1):853-60.

Palumbo PE, Raskino C, Fiscus S, Pahwa S, Fowler MG, Spector AS et al. Predictive value of quantitative plasma HIV RNA and CD4+ lymphocyte count in HIVinfected infants and children. J Am Med Assoc 1998;279:756-61.

Patton LL, McKaig R, Strauss R, Rogers D, Eron JJ Jr. Changing prevalence of oral manifestations of human immuno-deficiency virus in the era of protease inhibitor therapy. Oral Surg Oral Med Oral Pathol Oral radiol Oral End 2000;89(3):299-304.

Peres KGA, Bastos JRM, Latorre MRDO. Severidade de cárie em crianças e relação com aspectos sociais e comportamentais. Rev Saúde Pública 2000;34(4):402-8.

Petersen SG, Quinto TCP, Vieira AAB, Fornasari M. Manifestações orais em crianças portadoras de AIDS. Rev Bras Odontol 1993;50(5):10-5.

Pinheiro A, Marcenes W, Zakrzewska JM, Robinson PG. Dental and oral lesions in HIV infected patients: a study in Brazil. Int Dent J 2004;54(3):131-7.

Pinjon E, Sullivan D, Salkin I, Shanley D, Coleman D. Simple, inexpensive, reliable method for differentiation of Candida dubliniensis from Candida albicans. J Clin Microbiol 1998;36(7):2093-5.

Polacheck I, Strahilevitz J, Sullivan D, Donnelly S, Salkin IF, Coleman DC. Recovery of Candida dubliniensis from non-human immunodeficiency virus-infected patients in Israel. J Clin Microbiol 2000;38(1):170-4.

Pongsiriwet S, lamaroon A, Kanjanavanti S, Pattanaporn K, Krisanoprakornkit S. Oral lesions and dental caries status in perinatally HIV-infected children in Northern Thailand. Int J Pediatr Dent 2003;13:180-5.

Projeto SB Brasil 2003: Condições de saúde bucal da população brasileira 20022003: Resultados principais. Brasília: Ministério da Saúde, Secretaria de Atenção à Saúde, Departamento de Atenção Básica, Coordenação Nacional de Saúde Bucal; 2004. 
Ramos-Gomez F. Dental considerations for the paediatric AIDS/HIV patient. Oral Dis 2002;8(Suppl 2):49-54.

Ramos-Gomez FJ, Petru A, Hilton JF, Canchola AJ, Wara D, Greenpan JS. Oral manifestations and dental status in paediatric HIV infection. Int J Paediatr Dent 2000;10:3-11.

Ranganathan K, Reddy BV, Kumarasamy N, Solomon S, Viswanathan R, Johnson NW. Oral lesions and conditions associated with human immunodeficiency virus infection in 300 south Indian patients. Oral Dis 2000;6(3):152-7.

Rodero L, Boutureira M, Jauregui Rueda H, Monticelli A, Losso M, Davel G.

Susceptibility test for yeast isolated from oral candidosis in HIV patients. In: Abstracts of the Interscience Conference on Antimicrobial Agents and Chemotherapy; San Francisco; 1995. San Francisco; 1995 p. 96. [Abstract nº E63].

Rubinstein A. Acquired immunodeficiency in children. Pediatr Rev 1988;10(6):165-9.

Rubinstein A. HIV infections in infants and children. In: Holmes KK, ed. Sexually Transmitted Diseases, $2^{\text {nd }}$ edn. Mc Graw-Hill: New York, p.843-99, 1990.

Samaranayake LP, Cheung LK, Samaranayake YH. Candidiasis and other fungal diseases of the mouth. Dermatol Ther 2002;15:251-69.

Samaranayake LP. Superficial bucal fungal infections. Curr Opin Dent 1996;1:41522.

Samaranayake LP. Oral mycoses in HIV infection. Oral Surg Oral Med Oral Pathol 1992;73(2):171-80.

Samaranayake LP, Holmstrup P. Oral candidiasis and human immunodeficiency virus infection. J Oral Pathol Med 1989;18(10):554-64.

Samaranayake LP, MacFarlane TW. Bucal candidosis. London: Wright; 1990.

Samaranayake YH, Samaranayake LP. C.krusei: biology, epidemiology, pathogenicity and clinical manifestations of an emerging pathogen. J Med Microbiol 1994;41(5):295-310. 
Sánchez-Vargas LO, Ortiz-López NG, Villar M, Moragues MD, Aguirre JM, Cashat$\mathrm{Cruz} \mathrm{M}$ et al. Oral Candida isolates colonizing or infecting human immunodeficiency vírus-infected and healthy persons in México. J Clin Microbiol 2005:4159-62.

Sande MA, Volberding PA. Tratamento clínico da AIDS. 3a. ed. Rio de Janeiro: Revinter; 1995. 409p.

Santos LC, Castro GF, de Souza IP, Oliveira RH. Oral manifestations related to immunosuppression degree in HIV-positive children. Braz Dent J 2001;12(2):135-8.

Schiodt M, Pindborg JJ. AIDS and the oral cavity. Epidemiology and oral manifestations of HIV infection: a review. Int J Oral Maxillofac Surg 1987;16:1-14.

Scott GB, Hutto C, Makuch RW, Mastrucci MT, O'Connor T, Mitchell CD, et al. Survival in children with perinatally acquired human immunodeficiency virus type 1 infection. N Engl J Med 1989;321(6):1791-6.

Silva RA, Lopes FF, Barreto, MAS. Estudo clínico das manifestações orais da Síndrome de Imunodeficiência Adquirida Pediátrica. RGO 2002;50(1):7-11.

Souza IPR et al. Prevalência de cárie em crianças infectadas pelo HIV. Rev Bras Odontol Rio de Janeiro 1996;53(1):49-51.

Studen-Pavlovich D, Chigurupati R. Oral manifestations in HIV-infected children. Pa Dent J (Harrisb) 1997;64(2):17-23.

Sullivan D, Coleman D. Candida dubliniensis: an emerging opportunistic pathogen. Curr Top Med Mycol 1997;8(1-2):15-25.

Sullivan D, Coleman D. Candida dubliniensis: Characteristics and identification. J Clin Microbiol 1998;36:329-34.

Sullivan DJ, Westerneng TJ, Haynes KA, Bennett DE, Coleman DC. Candida dubliniensis sp. nov.: phenotypic and molecular characterization of a novel species associated with oral candidosis in HIV - infected individuals. Microbiol 1995;141:1507-21.

Sullivan DJ, Moran G, Donnelly S, Gee S, Pinjon E, McCartan B et al. Candida dubliniensis: an update. Rev Iberoamer Micol 1999;16:72-6. 
Tintelnot K, Haase G, Seibold M, Bergmann F, Staemmler M, Franz T, et al. Evaluation of phenotypic markers for selection and identification of Candida dubliniensis. J Clin Microbiol 2000;38(4):1599-608.

Tofsky N, Nelson EM, Lopez RN, Catalanotto FA, Fine DH, Katz RV. Dental caries in HIV-infected children versus household peers: two-year findings. Pediatr Dent 2000;22:207-14.

Torres RA, Barr M. Impact of combination therapy for HIV infection on inpatient census. N Engl J Med 1997;336:1531-2.

Tovo PA, de Martino M, Gabiano C, Cappello N, D'Elia R, Loy A, et al. Prognostic factors and survival in children with perinatal HIV-1 infection. The Italian Register for HIV Infections in Children. Lancet 1992;339(8804):1249-53.

Traumman T, Monteiro K. Dormindo com o inimigo. Rev Veja 1988;31(48):114-21.

Ugun-Can B, Kadir T, Akyuz S. Oral candidal carriage in children with and without dental caries. Quintessence Int 2007;38(1):45-9.

Valdez IH, Pizzo PA, Atkinson JC. Oral health of pediatric AIDS patients: A hospital based study. ASDC J Dent Child 1994;61:114-8.

Vargas KG, Joly S. Carriage frequency, intensity of carriage, and strains of oral yeast species vary in the progression to oral candidiasis in human immunodeficiency viruspositive individuals. J Clin Microbiol 2002;40(2):341-50.

Waldman HB. Almost eleven million special children. ASDC J Dent Child 1991;58:237-40.

Walker DM, Arendorf T. Candida leucoplakia, chronic multifocal candidosis and median rhomboid glossitis. In: Samaranayake LP, MacFarlane TW, editors. Oral candidosis. London: Wright; 1990. p.184-99.

Walsh J. International patterns of oral health care - the example of New Zealand. Zealand Dent J 1970;66:143-52. 
Walsh TJ, Müller FMC, Groll A, Gonzales C, Roilides E. Fungal infections in children with HIV. In: Pizzo AP e Wilfert CM. Pediatric AIDS. $3^{\text {rd }}$ ed. Baltimore: Lippincott; 1998 p. 183-204.

Weems JJ Jr. Candida parapsilosis: epidemiology, pathogenicity, clinical manifestations, and antimicrobial susceptibility. Clin Infect Dis 1992;14(3):756-66.

World Health Organization. Oral health surveys: basic methods. 4th ed. Geneva: World Health Organization; 1997.

Wilkes MS, Jacobs TA, Milberg J, Stoneburner R. Autopsy patterns in patients dying of acquired immunodeficiency syndrome in New York City. Arch Pathol Lab Med 1988;112(12):1221-23.

Willian DW, Lewis MAO. Isolation and identification of candida from oral cavity. Oral Dis 2000;6(1):3-11. 


\section{ANEXO A - Parecer do Comitê de Ética em Pesquisa}

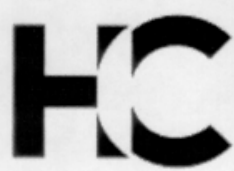

\section{IOSPITAL DAS GLINIGAS}

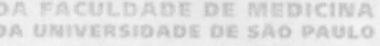

\section{APROVAÇÃO}

A Comissão de Ética para Análise de Projetos de Pesquisa - CAPPesq da Diretoria Clínica do Hospital das Clínicas e da Faculdade de Medicina da Universidade de São Paulo, em sessão de 08.06.05, APROVOU o Protocolo de Pesquisa $n^{\circ}$ 295/05, intitulado: "Prevalência e estudo das características fenotípicas e genotípicas da Candida dubliniensis isolada da cavidade oral de crianças com Aids" apresentado pelo Departamento de PEDIATRIA, inclusive o Termo de Consentimento Livre e Esclarecido.

Cabe ao pesquisador elaborar e apresentar à CAPPesq, os relatórios parciais e final sobre a pesquisa (Resolução do Conselho Nacional de Saúde n 196, de 10.10.1996, inciso IX. 2, letra "c")

Pesquisador(a) Responsável: Dra. Heloisa Helena de Sousa Marques Pesquisador (a) Executante: Dra. Carina Domaneschi

CAPPesq, 08 de Junho de 2005.

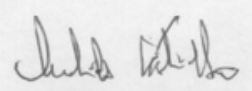

PROF. DR. EUCLIDES AYRES DE CASTILHO Presidente da Comissão de Ética para Análise de Projetos de Pesquisa

Comissão de Ética para Análise de Projetos de Pesquisa do HCFMUSP e da FMUSP 


\title{
ANEXO B - Parecer do Comitê de Ética em Pesquisa
}

\author{
UNIVERSIDADE DE SÃO PAULO \\ FACULDADE DE ODONTOLOGIA
}

\section{PARECER DE APROVAÇÃO \\ Protocolo 64/06}

Com base em parecer de relator, o Comitê de Ética em Pesquisa, APROVOU o protocolo de pesquisa "Prevalência e estudo das características fenotípicas e genotipicas da Cândida dubliniensis isolada da cavidade oral de crianças com Aids", de responsabilidade da Pesquisadora Carina Domaneschi, sob orientação da Professora Doutora Esther Goldenberg Birman.

Tendo em vista a legislação vigente, devem ser encaminhados a este Comitê relatórios anuais referentes ao andamento da pesquisa e ao término cópia do trabalho em "cd". Qualquer emenda do projeto original deve ser apresentada a este CEP para apreciação, de forma clara e sucinta, identificando a parte do protocolo a ser modificada e suas justificativas.

São Paulo, 07 de julho de 2006

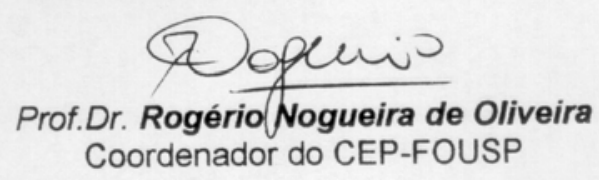

Av Prof Lineu Prestes, 2227 - Cidade Universitária "Armando de Salles Oliveira" CEP 05508-000 São Pauio - SP . Diretoria Telefax: (011)3091-0062/3091-7817/3091-7860 - Compras (011) 3091-7825 


\title{
ANEXO C - Termo de Consentimento Livre e Esclarecido
}

\author{
HOSPITAL DAS CLÍNICAS
}

DA

FACULDADE DE MEDICINA DA UNIVERSIDADE DE SÃO PAULO

TERMO DE CONSENTIMENTO LIVRE E ESCLARECIDO

(Instruções para preenchimento no verso)

I - DADOS DE IDENTIFICAÇÃO DO SUJEITO DA PESQUISA OU RESPONSÁVEL LEGAL

1. NOME DO PACIENTE:

DOCUMENTO DE IDENTIDADE No:

SEXO: M

DATA NASCIMENTO:

ENDEREÇO:

BAIRRO:

CEP:

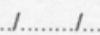

............. No

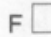
TELEFONE: DDD (.

CIDADE

APTO:

2.RESPONSÁVEL LEGAL

NATUREZA (grau de parentesco, tutor, curador etc.)

DOCUMENTO DE IDENTIDADE:

DATA NASCIMENTO:

ENDEREÇO

BAIRRO:

(...).

CEP

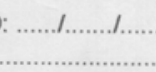

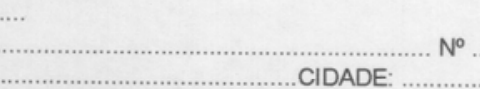
SEXO: M TELEFONE: DDD ..)

\section{II - DADOS SOBRE A PESQUISA CIENTÍFICA}

1. TÍTULO DO PROTOCOLO DE PESQUISA: "Prevalência e estudo das características fenotípicas e genotípicas da Candida dubliniensis isolada da cavidade oral de crianças com aids"

PESQUISADOR: Heloísa Helena de Sousa Marques

CARGO/FUNÇÃO: médica-assistente INSCRIÇÃO CONSELHO REGIONAL no. 27873/SP

UNIDADE DO HCFMUSP: Infectologia do Instituto da Criança

3. AVALIAÇÃO DO RISCO DA PESQUISA:

$\begin{array}{ll}\text { SEM RISCO } & \text { RISCO MINIMO (X) RISCO MÉDIO } \\ \text { RISCO BAIXO } \square & \text { RISCO MAIOR } \square\end{array}$

4.DURAÇÃO DA PESQUISA : 1 ano 
III - REGISTRO DAS EXPLICAÇÕES DO PESQUISADOR AO PACIENTE OU SEU REPRESENTANTE LEGAL SOBRE A PESQUISA, CONSIGNANDO:

1. Justificativa e os objetivos da pesquisa

Para que possamos verificar a prevalência do fungo na cavidade bucal da criança é necessário examinar sua boca. Os fungos são microorganismos que podem aparecer na boca em situações diversas como: uso prolongado de antibióticos, secura bucal, em indivíduos que usam dentadura, em pacientes $\mathrm{HIV+}$, entre outros. Devido a pouca informação do papel destes fungos na boca é importante sua identificação para melhorar o tratamento e a prevenção das lesőes bucais. Também será realizado o exame visual de cáries, para reconhecer a necessidade de tratamento odontológico desta criança.

2. Procedimentos que serão utilizados e propósitos, incluindo a identificação dos procedimentos que são experimentais.

Para coletar o material para identificação de fungos serão raspados as bochechas e as laterais da língua com o auxílio de uma espátula de madeira. Para que vejamos o índice de cárie será feito um exame utilizando um espelho clínico e uma sonda CPI (ponta arredondada na extremidade). Não há necessidade de anestesia, pois a coleta e o exame são rápidos, não provocam dor, sangramento ou dano físico ao paciente.

3. Desconfortos e riscos esperados

O exame pode causar nenhum ou mínimo grau desconforto ou risco ao paciente embora o método utilizado não seja invasivo.

4. Benefícios que poderão ser obtidos

Sabendo-se a prevalência deste fungo, sua patogenia e resistência a antifúngicos, poderemos atuar mais adequadamente no tratamento do paciente. Em relação ao diagnóstico de cárie, não há benefícios diretos em relação ao tratamento, mas o responsável será informado e orientado a procurar Serviço Odontológico especializado.

5. Procedimentos alternativos que possam ser vantajosos para o indivíduo.

Não se aplica. 


\section{IV - ESCLARECIMENTOS DADOS PELO PESQUISADOR SOBRE GARANTIAS DO SUJEITO DA} PESQUISA:

1. Acesso, a qualquer tempo, às informaçőes sobre procedimentos, riscos e benefícios relacionados à pesquisa, inclusive para dirimir eventuais dúvidas.

2. Liberdade de retirar seu consentimento a qualquer momento e de deixar de participar do estudo, sem que isto traga prejuizo à continuidade da assistência.

3. Salvaguarda da confidencialidade, sigilo e privacidade.

4. Disponibilidade de assistência no HCFMUSP, por eventuais danos à saúde, decorrentes da pesquisa.

5. Viabilidade de indenização por eventuais danos à saúde decorrentes da pesquisa.

\section{INFORMACÕES DE NOMES, ENDERECOS E TELEFONES DOS RESPONSÁVEIS PELO ACOMPANHAMENTO DA PESQUISA, PARA CONTATO EM CASO DE INTERCORRÊNCIAS CLÍNICAS E REAÇÕES ADVERSAS.}

Dra. Heloisa Helena de Sousa Marques - Av. Dr. Enéas de Carvalho Aguiar, no. 647. Tel: 11-30698673

Dra. Esther Goldenberg Birman - Faculdade de Odontologia - USP, Av: Prof. Lineu Prestes, 2227, Butantã.

Tel: 11-30917883

Dra. Carina Domaneschi - Faculdade de Odontologia - USP, Av: Prof. Lineu Prestes, 2227, Butantã. Tel: 11-30917883 ou 71249596

\section{OBSERVAÇÕES COMPLEMENTARES:}

Năo há previsăo de indenizaçőes ou pagamentos aos pacientes, pois este exame será feito no dia em que a criança passará pelo ambulatório das instituiçōes citadas sem necessidade de retorno.

Ao participar, concorda em cooperar com a pesquisa, durante o procedimento da coleta, com fotos se relevante ao trabalho, e permitindo o armazenamento deste material para futuros trabalhos năo abrindo mão de seus direitos legais ao assinar o termo de consentimento informado, podendo retirá-lo a qualquer momento, se julgar conveniente.

\section{VII - CONSENTIMENTO PÓS-ESCLARECIDO}

Declaro que, após convenientemente esclarecido pelo pesquisador e ter entendido o que me foi explicado, consinto em participar do presente Protocolo de Pesquisa.

São Paulo, de de 2 


\section{ANEXO D - Ficha Clínica}

\section{FICHA CLÍNICIA n.}

Nome:

Sexo: $M() \quad F() \quad$ Idade: ___ Data de nascimento:

Numero do prontuário:

Telefone:

Dados da coleta:

Data:

Local da coleta: ( ) mucosa bucal ( ) outros Localização:

Meio de cultivo:

História méciica, medicação:

\section{Carga Viral (CV): \\ CD4 cel/ $\mathrm{mm}^{3}$ : \\ CD8 celi/mm ${ }^{3}$ :}

Relação CD4/CD8:

\section{Exame extra-bucai:}

Linfonodos palpáveis: não( ) sim( ) Localização:

\section{Exame intra-bucal:}

Lesão: ausente ( ) presente ( )

Diagnóstico provável:

Localização:

Descrição da lesão:

Tratamento: não ( ) $\operatorname{sim}($ ), qual (is): 


\title{
ANEXO E - Ficha micologia
}

\author{
INSTITUTO DE CIE்NCIAS BIOMĖDICAS \\ DEPARTAMENTO DE MICROBIOLOGIA \\ SEÇȦO DE MIICOLOGIA \\ DIVISÃO DE LEVEDURA
}

Procedéncia:

Registro:

Observaçōes:

1. Exame direto:

2. Cescimento $\mathrm{cm}$ meios usuais:

Crescimento em meios com ácido graxo:

3. Microcultivo e tubo germinativo:

$\begin{array}{llll}\text { PM: } & \text { BL: } & \text { AR: } & \text { AR: } \\ \text { MV: } & C L: & \text { Outros: } & \end{array}$

4. Ascos e ascosporos:

Positivos:

5. Outras Provas

-Sintese amido:

-Produção melanina:

-TTC:

6. Auzanograma

$\mathrm{KNO}_{3}$

PEP

glicose:

inositol:

sacarose:

lactose:

dulcitol:

rafinose:

celobiose:

melibiose:

trealose:

ramnose:

maltose:

silose:

7. Zimograma

glicose:

lactose:

maltose:

sacarose:

Diagnóstico: 
ANEXO F - Levantamento epidemiológico

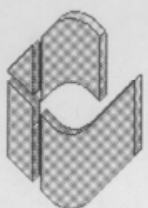

LEVANTAMENTO EPIDEMIOLÓGICO INSTITUTO DA CRIANÇA - HC/USP

\begin{tabular}{|c|c|}
\hline $\begin{array}{l}\text { A) Grau de instrução do responsável } \\
\text { (cuidador): }\end{array}$ & B) Renda mensal familiar: \\
\hline C) Possui residência: & $\begin{array}{l}\text { D) Número de pessoas que residem na } \\
\text { casa: }\end{array}$ \\
\hline E) Número de cômodos na casa: & F) Número de irmãos: \\
\hline G) A criança já foi ao dentista: & H) Freqüência da higiene bucal: \\
\hline I) A escova é só da criança: & $\begin{array}{l}\text { J) Com que freqüência a criança come } \\
\text { doces, sucos ou alimentos com açúcar? }\end{array}$ \\
\hline K)Refrigerantes (freqüência): & \\
\hline $\begin{array}{l}\text { L) Com que freqüência à criança toma } \\
\text { leite?: }\end{array}$ & $\begin{array}{l}\text { M) Se sim o responsável coloca } \\
\text { açúcar?: }\end{array}$ \\
\hline N) A criança toma leite à noite?: & O) Se sim, realiza higiene oral após?: \\
\hline \multicolumn{2}{|l|}{ Q) Acesso ao dentista: } \\
\hline $\begin{array}{l}0 \text { - não Pq? } \\
1 \text { - dentista particular }\end{array}$ & 2 - dentista do Serviço Público \\
\hline \multicolumn{2}{|c|}{ R) Quem executa a higiene oral da criança: } \\
\hline $\begin{array}{l}0 \text { - não executa } P q ? \\
1 \text { - a criança }\end{array}$ & $\begin{array}{l}2 \text { - cuidador } \\
3 \text { - ambos }\end{array}$ \\
\hline \multicolumn{2}{|l|}{ S) Recursos para a higiene bucal: } \\
\hline $\begin{array}{l}0 \text { - nenhum } \\
1-\text { escova dental }\end{array}$ & $\begin{array}{l}2 \text { - creme dental } \\
3 \text { - fio dental } 4 \text {-enxaguatorios }\end{array}$ \\
\hline \multicolumn{2}{|c|}{ T) O senhor (a) diria que os dentes da criança são: (percepção bucal) } \\
\hline $\begin{array}{l}0 \text { - não sabe } \\
1 \text { - ruins } \\
2 \text { - regulares }\end{array}$ & $\begin{array}{l}3 \text { - bons } \\
4 \text { - muito bons }\end{array}$ \\
\hline
\end{tabular}




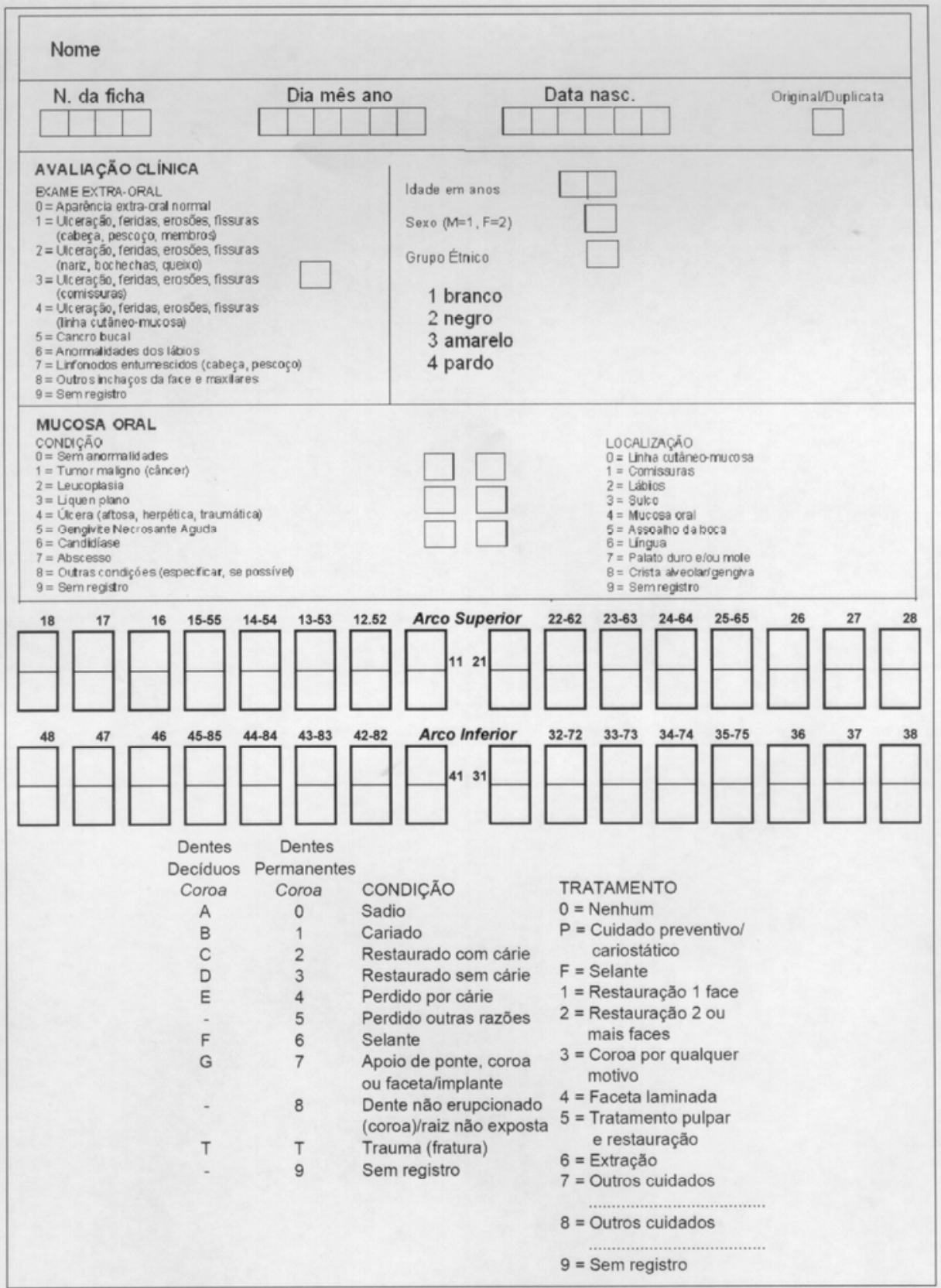

